\title{
Ethnic Identities, Public Spending and Political Regimes ${ }^{1}$
}

\author{
By Sugata Ghosh and Anirban Mitra ${ }^{2}$
}

August 2021

\begin{abstract}
Do democracies discriminate less against minorities as compared to non-democracies? How does the dominance of an ethnic group affect discrimination under various political regimes? We build a theory to analyse such questions. In our model, political leaders (democratically elected or not) decide on the allocation of spending on different types of public goods: a general public good and an ethnically-targetable public good which benefits the majority ethnic group while imposing a cost on the other minorities. We show that, under democracy, lower ethnic dominance leads to greater provision of the general public good while higher dominance implies higher provision of the ethnicallytargetable good. Interestingly, the opposite relation obtains under dictatorship. This implies that political regime changes can favour or disfavour minorities based on the ambient level of ethnic dominance. Several historical events involving regime changes can be analysed within our framework and are consistent with our results.
\end{abstract}

JEL codes: D72, D74, H40

Keywords: Ethnic identities, Discrimination, Public spending, Political regimes.

\footnotetext{
${ }^{1}$ We thank Maria Garcia-Alonso, Bård Harstad, Sugata Marjit, Halvor Mehlum, Ajit Mishra, Shabana Mitra, Siddhartha Mitra, Kalle Moene, Fabien Moizeau, Sanna Nurmikko-Metsola, Sarmistha Pal, Torsten Persson, Debraj Ray, Alessia Russo, Petros Sekeris, Kjetil Storesletten and Zaki Wahhaj for constructive comments.We also thank participants of the European Public Choice Society Meeting 2014 (Cambridge, UK), the 10th Annual Conference on Economic Growth and Development (ISI Delhi, 2014), the RES Annual conference 2015 (Manchester), the EEA-ESEM conference 2016 (Geneva), the XXVIIIth Annual Conference on Contemporary Issues in Development Economics (Jadavpur University 2017), the CSAE Conference 2019 (University of Oxford) the Workshop on Institutions (2019) at Ashoka University and the 16th PEARL conference (Rennes) for helpful feedback. Mitra acknowledges that while carrying out part of this research, he has been associated with the Centre of Equality, Social Organization and Performance (ESOP) at the Dept. of Economics (U. of Oslo). ESOP is supported by the Research Council of Norway through its Centres of Excellence funding scheme, project number 179552. The usual disclaimer applies.

${ }^{2}$ Ghosh: Brunel University; Mitra: University of Kent, email: A.Mitra@kent.ac.uk.
} 


\section{Introduction}

Discrimination against minorities — ethnic, religious, linguistic, etc. - is a serious concern worldwide. Sometimes such discrimination takes an overt form via directed violence, forcible segregation (residential and or occupational). ${ }^{3}$ In many contexts this is more covert, working through discrimination in the labour market (manifest in hiring decisions, glass ceilings, etc.) or even through the public offices by provision of lower/inferior public goods (roads, infrastructure, health facilities, educational institutions, etc.). Such systematic exclusion of segments of the population is damaging not only from a normative perspective - there are potential economic inefficiencies arising out of this. The role of political institutions in determining various economic outcomes has received much attention in the recent years. ${ }^{4}$ Typically, democracies are perceived to be superior to non-democracies on many dimensions; particularly, on the allocation of public spending (see e.g., Tavares and Wacziarg (2001), Deacon (2009), Acemoglu et al. (2014)). So can the issue of discrimination against minorities be mitigated by superior institutional structures like democracy? In other words, is discrimination necessarily lower under democracies as opposed to dictatorships? Recent events suggest otherwise. Consider the recent surge in violence against the Muslim Rohingya community in Myanmar - this is after a democratically elected government assumed power. ${ }^{5}$ Therefore, can one pin down which factors might condition the degree of discrimination under different political regimes? In particular, how does the presence of a dominant ethnic group affect discrimination under various political regimes? Here, we put forward a tractable theory to answer such questions.

Our theory considers two alternative political regimes: democracy and dictatorship. In our model, the society is composed of a dominant ethnic group and an amalgamation of many other (minority) groups. Irrespective of the political regime, one of the main tasks of the government is to allocate public spending. Such spending has an important role to play in the economy, particularly in boosting output and economic growth. ${ }^{6}$ Political parties within a democracy would understandably take this spending seriously, as their terms in office would depend quite critically on this. For dictators, who are not elected through popular mandate, there is an alternative incentive to direct public spending in a certain way: they would typically embezzle a portion for themselves, while also

\footnotetext{
${ }^{3}$ Consider the centuries old "caste" system in India. Incidents of atrocities upon the lower castes are not uncommon even today whenever there is an alleged "transgression" of the boundaries by them.

${ }^{4}$ Persson (2002) contains an excellent overview.

${ }^{5}$ The increase in inter-ethnic cooperation in Rwanda under President Kagame's quasi-autocratic rule (see Blouin and Mukand (2019)) also points in a similar direction. We shall turn to a detailed discussion of such events later.

${ }^{6}$ See, for instance, Barro (1990), Futagami et al. (1993), Turnovsky (1997), Ghosh and Roy (2004), etc.
} 
ensuring that they minimise the chances of a popular uprising.

We introduce the notion of discrimination in this setting in the following manner: two kinds of public spending are possible in this society. The first type is on a "general" public good which benefits everyone irrespective of their ethnic background, while the other, an "ethnic" public good, benefits only the dominant ethnic group. ${ }^{7}$ Moreover, this latter good apart from being exclusionary imposes a direct cost (psychological, material, etc.) on the members of the non-dominant ethnic groups. Instances of such targetting are not difficult to come by - e.g., a formal proclamation of ethnic identities, in particular delineating the national identity in terms of that of the dominant ethnic group (via the funding of ethnic or cultural-specific goods, festivals, etc.), which would reduce the stature of the minorities to "second class citizens". Hence, whenever there is a positive amount spent on the ethnic good, it is classified as discrimination in our setup - the greater the spending on the ethnic good, the higher the discrimination. ${ }^{8}$ Given that this "ethnic good" is actually publicly provided, the theory we develop is pertinent to overt forms of discrimination - specifically, where the state has the potential to favour certain segments of society at the cost of others. There is, however, heterogeneity in the preferences for this "ethnic" good within the dominant ethnic group - some value it more than others.

We first study a democratic setting with two parties which compete for the citizens' votes by each proposing tax rates on incomes and thereby promising budgetary allocations on the two public goods. Like in Acemoglu and Robinson (2006), we assume that citizens of any ethnic group can either be poor or rich. Here, we show that the equilibrium allocation of public spending depends heavily upon the extent of ethnic dominance. Below a certain threshold level of ethnic dominance, the entire budget is spent on the general public good; above this threshold, the spending is entirely on the ethnic public good. This is intuitive, as in the absence of a "large" dominant group, political parties will strive to compete for votes from all sections of the population (and hence invest in the general public good), while in the presence of such a group, the parties would spend all of their energies in catering to that group (thereby investing in the ethnic good) even at the cost of antagonising the minorities. The fact that parties can adjust the tax rate suitably to garner support among the different income groups does not interfere with this core logic.

In the case of a dictatorial regime, there is no explicit role for political parties. The dictator decides on the tax rate and the allocation of public spending with largely two considerations in mind: appropriation of the public funds ("rents") and surviving

\footnotetext{
${ }^{7}$ Section 4 discusses the case of having an ethnic good for each of the minority groups.

${ }^{8}$ To be sure, this is a stylised view of the idea of discrimination. Nonetheless, this is the aspect which is salient through the actions of the government; hence, we think it is a relevant depiction.
} 
any potential uprising by the citizens. In the eventuality of a successful revolt, there is a return to the two-party democratic regime and the dictator is disallowed from appropriating any amount of the public budget. Thus, the dictator has to factor in how the different income earners within the ethnic groups will react - i.e., support a rebellion or not - when he makes his public spending allocation. Clearly, the decision by any citizen would depend upon what she thinks the alternative scenario (in this case, democracy) will deliver to her. Since, whatever democracy delivers depends upon how large the dominant ethnic group the society is, the dictator effectively operates in this "shadow of democracy". Therefore, the dictator's actions also depend upon the level of ethnic dominance.

We show that when ethnic dominance is lower than a certain threshold, the dictator tilts spending (if any) entirely towards the dominant ethnic group. ${ }^{9}$ When ethnic dominance is sufficiently high, the dictator may invest only in the general public good; in fact, the spending on the ethnic good (if any) is strictly lower than that under democracy. In other words, in society with little ethnic dominance the dictator will actually only cater to the dominant ethnicity while neglecting the minorities. It is precisely a society with a large dominant ethnic group which will witness little or no discrimination. Observe that this is completely contrary to the equilibrium policy under democracy.

The intuition for this result is the following: with low ethnic dominance, the minority group has a strong incentive to rebel since they know that they will benefit from the general public spending in case the dictator is ousted and elections take place. So dissuading them is too costly for the dictator. In order to prevent members of the dominant group from joining the rebellion, targetted ethnic spending has to be offered to that group by the dictator. Alternatively, the dictator may simply cater to the rich citizens by lowering tax rates and not providing any public spending.

Conversely, with high ethnic dominance, the dominant group has an incentive to rebel since under democracy the entire spending will be directed towards them (maximum possible discrimination). In this situation, the minority group will typically not rebel since democracy will not bring them any enjoyment of the public spending. Therefore, in order to dissuade some members of the majority from rebelling, a positive amount of only the general public good may be offered by the dictator. Discrimination need not be optimal from the dictator's perspective since under democracy the entire spending would be in favour of the dominant ethnic group. Hence the dictator tries to dissuade rebellion by committing to little or no discrimination. As a result, the pattern of discrimination - particularly, how it varies with the size of dominant ethnic majority

\footnotetext{
${ }^{9}$ This threshold corresponds to the one in democracy below which general public spending is the only equilibrium allocation.
} 
— is strikingly different in a democracy as opposed to a dictatorship.

In our setup, the extent of appropriation is an endogenous choice variable for the dictator. This allows us to document the relationship between ethnic dominance and this level of appropriation by the dictator. Our results provide a rationale - based on the size of the dominant ethnic group - for why one observes a different pattern of discrimination and not just a different level of public spending in dictatorships as opposed to democracies.

Our theory can be used to interpret certain historical events like the changing nature of Hutu-Tutsi relations in Rwanda, the treatment of Chinese Indonesians during and after the Suharto regime and more recently the issue of persecution of the Rohingya community in Myanmar and that of Muslim citizens in India. Each of these scenarios when viewed through the lens of our model appear to be consistent with the model's predictions. We offer a more detailed treatment of each of these cases later.

The remainder of the paper is organised in the following way: Section 2 provides a discussion of the related literature. Section 3 develops the theory and presents the analytical results. Section 4 discusses a possible extension, Section 5 contains some discussion regarding certain historical events in light of our theory and Section 6 concludes. All proofs are contained in the appendix.

\section{Related Literature}

By highlighting the connection between discriminatory public spending and political regimes within the context of ethnic dominance, our paper relates to various strands of literature. The link between ethnic diversity and public goods provision draws upon the recognition of the fact that when people are heterogeneous, so are their preferences, which thereby has an important bearing on how much and what sort of public goods are produced. For instance, the link between ethnic fractionalisation and public services is attributed to taste differences of different sections of the population (Alesina et al. (1999), Alesina and La Ferrara (2005)) and/or inability to impose social sanctions in ethnically diverse communities (Miguel and Gugerty (2005)), thus leading to failure of collective action. ${ }^{10}$ In most of this literature, the focus has been on coordination issues arising from taste diversity. The issue of how various minority groups fare from such

\footnotetext{
${ }^{10}$ Banerjee and Somanathan (2001), in studying the Indian districts, have suggested that more heterogeneous communities tend to be politically weaker, and therefore are likely to be denied the public goods of their choice and are more likely to get some of the inferior substitutes. See also Tajfel et al. (1971), Alesina and Drazen (1991), Alesina and Rodrik (1994), Alesina et al. (1999), Baldwin and Huber (2010) among others.
} 
public provision has largely been neglected.

A large section of the literature on discrimination against minorities deals with the evaluation of various corrective measures. These measures typically involve some form of earmarking or reservation of posts (often in public offices, educational institutions, etc.). Reserving political office for members from various marginalised groups has sometimes been found to be effective - in the sense of working in the interests of those groups (see e.g., Pande (2003), Chin and Prakash (2011) for evidence in the case of India where reservation has been in place for decades in favour of historically disadvantaged groups called the Scheduled Castes (SCs) and the Scheduled Tribes (STs).) There are other studies which suggest that the effects may be heterogeneous within the minorities (Mitra (2018)) or that they may not be persistent (Jensenius (2015), Bhavnani (2017)). But most of this literature is in the context of democracies; there is hardly any comparison with alternative political regimes. Also, these studies do not deal with how the political structure may be responsible for the existence of such discrimination in the first place.

Mukand and Rodrik (2015) make the distinction between electoral and liberal democracies where the former "are political regimes which allow political competition and generally fair elections, but exhibit considerable violations in the civil rights of minority and other groups not in power." In their words, the main distinctive feature of a liberal regime is the presence of "the restraints placed on those in power to prevent discrimination against minorities and ensure equal treatment". They develop a formal model to sharpen the contrast between electoral and liberal democracies and highlight circumstances under which liberal democracy can emerge. Their emphasis on distinguishing between different regimes (electoral and liberal democracies) in terms of the discrimination against minorities resonates with the main theme in our work. However, their focus is different from ours - they outline the conditions as to when liberal democracy may arise.

Padro-i-Miquel (2007) argues how it is possible for rulers who often extract enormous rents and grossly mismanage their economies to survive. This is possible in an environment where society is ethnically divided and institutions are weak. The incumbent ruler can exploit the members of his own ethnic group by the utilising "the politics of fear". Whilst being related to the issue of discrimination against minorities, the logic therein does not rely upon one group being numerically/politically dominant; this is a key departure from our setup. Moreover, our comparison across different regimes (democracy and dictatorship) is not the focus in Padro-i-Miquel (2007). Burgess et al. (2015) does perform a comparison across regimes. They find, in the context of Kenya during the 1963 - 2011 period, strong evidence of ethnic favouritism in road-building 
during periods of autocracy. ${ }^{11}$ Interestingly, this form of ethnic favouritism disappeared during periods of democracy. In our paper, the dictator is only interested in increasing their rent from the national pie, and we have abstracted away from any non-pecuniary payoffs (like favouring co-ethnics per se). Our model is not concerned with the ethnic identity of the political leader unlike Burgess et al. (2015) and Padro-i-Miquel (2007). When it comes to democracy, our results are in a sense comparable to the papers cited here, but this is due to political competition between parties for the support of both rich and poor citizens rather than the ethnicity of the elected representative.

Our work is related to Deacon (2009) where the differing incentives of political leaders from different regimes (democracy/dictatorship) are discussed in a theoretical framework. Deacon (2009) also provides robust empirical evidence on the asymmetries in public spending across the different political structures.

On the subject of whether or not the nature of spending is monotonic in ethnic diversity, our paper is close to Fernandez and Levy (2008). They show how diversity in preferences affects the basic conflict between rich and poor in a framework where people are heterogeneous both in preferences and in incomes, and in which political parties and party platforms are endogenous. However they do not deal with an autocratic setup and hence do not engage with a comparison across regimes for minorities.

\section{The Model}

Here, we develop a simple model to capture the link between public spending (general versus discriminatory) and ethnic dominance under different political structures. Our basic structure borrows heavily from Acemoglu and Robinson (2006). Our framework will enable a direct comparison of public spending patterns across a democracy and a dictatorship for any level of ethnic dominance. We begin by describing the environment and then proceed to the analysis of a democratic setup. This will lead us to the analysis for the dictatorship scenario.

\subsection{The environment}

There is a unit mass of citizens in the economy which is partitioned into $N \geq 2$ ethnic groups. Of these, we will call the largest one the dominant ethnic group and denote its mass by $\lambda \in(0,1)$. We refer to the remaining mass $(1-\lambda)$ of ethnic groups as being

\footnotetext{
${ }^{11}$ Those districts that shared the ethnicity of the president received twice as much expenditure on roads and almost five times the length of paved roads built relative to what would be predicted by their population share.
} 
minorities, although collectively they may be larger than the dominant ethnic group (i.e., $\lambda$ may well be below $1 / 2$ ). Our measure of ethnic dominance is essentially the magnitude of $\lambda$.

There is heterogeneity in terms of income in the society. Like in Acemoglu and Robinson (2006) we have two income levels $-y^{p}$ for the poor and $y^{r}$ for the rich such that $y^{p}<y^{r}$. Let $\pi$ denote the mass of the poor where $\pi \in(1 / 2,1)$. Denote the average income by $\bar{y}$ where $\bar{y} \equiv \pi y^{p}+(1-\pi) y^{r}$. We start with the assumption of unranked ethnicity a la Esteban and Ray (2008), i.e., the proportion of poor citizens among the dominant ethnic group is the same as that in the entire society, namely $\pi$.

The political process determines an income tax rate - call it $t \in[0,1]$ - which generates a budget for providing the citizens with public goods. Now, the budget could be spent on two different public goods. One is a truly general public good call it $G$ - investment in which benefits all citizens equally. The other is an ethnicspecific good $E$, designed to benefit only members of the dominant ethnic group, i.e., the $\lambda$-group. We will assume that the members of the minority actually are harmed by the provision of $E$; this is because providing $E$ implies discriminating against the minorities.

We think of $E$ as a component of public policy which promotes - on average - the economic/social/political interests of the dominant ethnic group to the detriment of the others. This could take diverse forms - say, in the promotion of the dominant ethnic group in economic spheres which disadvantages the other ethnic groups by facilitating their skill acquisition/raising the barriers for minorities in terms of access to formal credit, etc. Alternatively, this could be embodied in a programme of carving out a "national identity" in terms of that of the dominant ethnic group - via the funding of ethnic or cultural-specific goods and festivals or raising the status of some attribute (say, language) of the dominant ethnic group over the others. These actions would clearly serve to reduce the economic and social stature of the minorities. This could also take the shape of intimidation and directed violence against various sections of the minorities either by the direct (mis)use of the armed forces or their complicity in not containing "mob violence" against the minorities. ${ }^{12}$

We assume that there is heterogeneity in preference for the ethnic-specific good $E$ within the dominant ethnic group. A policy is denoted by $(t, g, e)$ where $t$ is the tax rate and $g$ and $e$ are the (per-capita) provisions of $G$ and $E$, respectively. The payoffs to the citizens are described below.

On being offered $(t, g, e)$, the payoff to member $i$ of the $(1-\lambda)$ - group is $(1-t) y^{i}+g-\psi \cdot e$ where $\psi \in[0,1]$. Higher the value of $\psi$, the greater the disutility to this minority group

\footnotetext{
${ }^{12}$ This is discussed in greater detail in Section 5 .
} 
member from discrimination. In a sense, this parameter $\psi$ captures the direct costs of discrimination to a minority group member. ${ }^{13}$ On the other hand, the payoff to a member $i$ of the $\lambda$-group is given by

$$
(1-t) y^{i}+g+e\left(1+\epsilon_{i}\right)
$$

where $\epsilon_{i}$ is drawn from a distribution with $\operatorname{cdf} F$ independently for every individual $i$ in the $\lambda$-group. The mean of $\epsilon$, denoted by $\bar{\epsilon}$, is assumed to be strictly positive and $f \equiv F^{\prime}>0$ everywhere on the real line. Moreover, we assume that $f$ is symmetric and unimodal so that the mode is at $\bar{\epsilon}$. This implies $F(0)<\frac{1}{2}$. This re-iterates the fact that it is more likely for a member (of the dominant group) to actually have a positive realisation of $\epsilon$, than not.

Observe that the ethnic-specific good $E$, with its element of taste-heterogeneity, easily lends itself to the following interpretations. One could think of different scenarios where the dominant ethnic group specialises (or has disproportionate shares) in a certain sector/industry. Hence, increasing investment in $E$ would by and large benefit most members of the group but not all; some might actually be hurt if their fortunes are tied to other sectors/industries. Alternatively, one could think of this $\lambda$-group as being composed of smaller ethnically distinct sub-groups who are united in their common affinity for $E$. So the ethnic good $E$ could be viewed as a kind of "compromise" local public good for this $\lambda$-group, where every member of the $\lambda$-group has a positive expected return from consuming $E$, which is equal ex ante. ${ }^{14}$ From the perspective of the minority citizens, $E$ is something whose benefits they are excluded from and yet whose costs are borne by them through the taxes paid. Furthermore, they are hurt by the provision of it since it signifies discrimination against them.

We employ the following tie-breaking rule: when two policies $\left(t_{1}, g_{1}, e_{1}\right)$ and $\left(t_{2}, g_{2}, e_{2}\right)$ with $t_{1} \neq t_{2}$ offer a citizen the same payoff, then the one with the lower tax rate is preferred by the citizen. ${ }^{15}$

\subsection{Democracy}

Here we will assume that there are two (exogenously given) political parties, $A$ and $B$ who compete for votes from the citizens. The budget constraint - for either of the

\footnotetext{
${ }^{13}$ It is possible to allow for heterogeneity in this discrimination cost across individuals. This is dealt with in detail in Section 4.

${ }^{14}$ This aspect of an ethnic group having it's own specific type of "local" public good is similar in spirit to Fernandez and Levy (2008).

${ }^{15}$ Assuming this, rather than have the citizen choose by tossing a fair coin, makes the algebra simpler.
} 
two parties - is given by

$$
\lambda . e+g \leq t \bar{y}
$$

We will denote party $j^{\prime}$ s platform by $\left(t_{j}, g_{j}, e_{j}\right)$ for $j=A, B$. The parties simultaneously propose platforms, and each party seeks to maximize its expected number of votes given the other party's platform. The four sub-groups in society are denoted by $(p, \lambda),(r, \lambda)$, $(p, 1-\lambda)$ and $(r, 1-\lambda)$ where $(p, \lambda)$ refers to the poor within the dominant ethnicity and the other three are interpreted analogously.

Now we are in a position to analyse the equilibrium of this simple game and then study its dependence on $\lambda$. In fact, the following observation is a step in that direction.

OBSERVATION 1. There exists a unique $\hat{\lambda} \in\left(1-\frac{1}{2 \pi}, 1\right)$, such that both parties proposing a tax rate of unity and promising to spend the entire budget on the public good $G$ is the unique equilibrium for every $\lambda \in(0, \hat{\lambda}]$.

The intuition behind the result stated in Observation 1 is the following. When the dominant ethnic group is actually small so that the $(p, 1-\lambda)$ group is a majority (i.e. $\pi(1-\lambda) \geq 1 / 2$ ), then the equilibrium policy must be the "bliss point" of this group. Hence, for $\lambda \leq 1-\frac{1}{2 \pi}$, the equilibrium policy involves $(t=1, g=\bar{y}, e=0)$. As $\lambda j u s t$ exceeds $1-\frac{1}{2 \pi}$, it is still not optimal from a party's perspective to shift away from $(t=1, g=\bar{y}, e=0)$. A reduction in $t$ (and hence $g$ ) while keeping $e=0$ would be welcomed by the rich, but not by the poor - so that is not an optimal deviation given that the poor outnumber the rich. Keeping $t=1$ and switching to $e>0$ will not work either since not everyone within the dominant ethnic group actually likes the ethnic good. Hence, $(t=1, g=\bar{y}, e=0)$ remains the optimal strategy for a range of $\lambda$ in excess of $1-\frac{1}{2 \pi}$.

We now ask if it is possible to have the "ethnic spending counterpart" to the result in Observation 1 - namely, that the tax rate is maximal and the entire budget is spent on the ethnic-specific good $E$ as an equilibrium outcome in the political competition game. The next observation provides an answer.

OBSERVATION 2. There exists a unique $\bar{\lambda} \in(1 / 2,1)$, such that both parties proposing a tax rate of unity and promising to spend the entire budget on the ethnic-specific good $E$ is the unique equilibrium for every $\lambda \in[\bar{\lambda}, 1)$ provided that $\pi$ is sufficiently high.

The preceding result informs us that there is indeed a threshold level for $\lambda$ - i.e., the mass of the dominant ethnic group — such that maximal provision of the ethnicspecific good is the only equilibrium strategy for each political party. It is however, important to note that this is not without any qualifications. Specifically, the size of 
the poor in society has to be sufficiently large for this result to hold. ${ }^{16}$

The driving force behind this result is the following. The poor in general prefer higher tax rates and redistribution. In the case of the dominant ethnic group, redistribution in the form of $E$ is desired by most of the poor within the group. Hence, taxing fully and providing $E$ wins the support of most of that group and also some of their rich counterparts. The other citizens (i.e., from the non-dominant groups) do not vote for this platform against any other feasible one; but, as long as $\lambda$ is sufficiently high, both political parties neglect them. This result reflects the incidence of "the tyranny of the majority" in a particularly stark fashion.

To simplify exposition, we introduce the following notation. We will denote the platform of $(t=1, g=\bar{y}, e=0)$ by $s_{G}$ and that of $(t=1, g=0, e=\bar{y} / \lambda)$ by $s_{E}$. These are the two benchmark platforms signifying maximum discrimination and pure non-discriminatory redistribution, respectively, and hence will re-appear often in the subsequent discussion.

At this point, we wish to clarify the definition of $\hat{\lambda}$. This is the upper bound, pertaining to the mass of the dominant ethnic group, the transcension of which implies that maximal provision of the general public good is no longer the unique equilibrium strategy for both parties. In other words, beyond $\hat{\lambda}$ it is possible for some other strategy to beat the platform of $s_{G} \cdot{ }^{17}$ Recall, this is the platform which the poor among the non-dominant groups prefer the most.

Intuitively, as $\lambda$ starts to increase beyond $1-\frac{1}{2 \pi}$, trying to win by appealing to all but the $(p, 1-\lambda)$ group starts becoming a viable strategy. This can be done by lowering taxes and providing $E$ - the former aspect will appeal to the rich (regardless of ethnic identity) and the latter aspect is attractive to a majority of the dominant ethnic group. Hence, a platform geared towards winning the support of the $(r, 1-\lambda)$ and the $\lambda$ group forms the basis for the definition of $\hat{\lambda}$. To that end, consider the generic platform $(t<1, e=t \bar{y} / \lambda, g=0)$ against $s_{G}$.

Note, the $(r, 1-\lambda)$ group will support iff

$$
(1-t) y^{r}-\psi \cdot \frac{t \bar{y}}{\lambda} \geq \bar{y} \Rightarrow t \leq \frac{y^{r}-\bar{y}}{y^{r}+\frac{\psi}{\lambda} \bar{y}} .
$$

A citizen $i$ from the $(j, \lambda)$ group $(j \in\{p, r\})$ will vote for the former over $s_{G}$ iff

$$
(1-t) y^{j}+\frac{t \bar{y}}{\lambda}\left(1+\epsilon_{i}\right) \geq \bar{y}
$$

\footnotetext{
${ }^{16}$ The precise threshold is defined in the proof contained in the Appendix.

${ }^{17}$ This justifies our earlier implicit assertion that $\hat{\lambda} \leq \bar{\lambda}$.
} 
Thus, the proportion of the $\lambda$ group in favour of this platform against $s_{G}$ is given by

$$
(1-\pi)\left[1-F\left(\frac{\lambda\left[\bar{y}-(1-t) y^{r}\right]}{t \bar{y}}-1\right)\right]+\pi\left[1-F\left(\frac{\lambda\left[\bar{y}-(1-t) y^{p}\right]}{t \bar{y}}-1\right)\right] .
$$

Call the above expression $V(t)$, thereby making it's dependence on $t$ explicit. Hence, the overall support for this platform against $s_{G}$ is

$$
(1-\pi)(1-\lambda)+\lambda V(t)
$$

provided $t \leq \frac{y^{r}-\bar{y}}{y^{r}+\frac{\psi}{\lambda} \bar{y}}$

Let $t^{\lambda} \equiv \arg \max V(t)$. We define $t_{0}$ as $\min \left\{t^{\lambda}, \frac{y^{r}-\bar{y}}{y^{r}+\frac{y}{\lambda} \bar{y}}\right\}$. Consider the following equation:

$$
(1-\pi)(1-\lambda)+\lambda V\left(t_{0}\right)=\frac{1}{2}
$$

The LHS is the total support for the platform $\left(t_{0}, e=t_{0} \bar{y} / \lambda, g=0\right)$ against $s_{G}$. We look for a solution in terms of $\lambda$ to equation (1) - that is an obvious candidate for $\hat{\lambda}$ a la Observation 1. ${ }^{18}$ We will denote this solution - if it exists - by $\lambda_{0}$.

LEMMA 1. $\lambda_{0}$ is increasing in $\psi$.

The above lemma informs that higher the marginal discrimination, the greater the threshold - in terms of ethnic dominance - required for the platform $\left(t_{0}, e=t_{0} \bar{y} / \lambda, g=\right.$ 0 ) to win against $s_{G}$. The basic reasoning is the following: greater distaste for discrimination makes it more difficult to convince members of the $(1-\lambda)$ group to support such a platform against $s_{G}$.

An immediate corollary of Lemma 1 is that it is possible - depending upon other parameters - that $\lambda_{0}<\frac{1}{2} .{ }^{19}$ In other words, it may be the case that $s_{G}$ is not the winning platform even when the size of the dominant ethnic group is less than $50 \%$ of the total population. Thus, discrimination against the non-dominant ethnic groups is a real possibility under democracy even when the dominant group does not constitute a majority in the society.

Lemma 2. For $\psi$ sufficiently high, there is no $\lambda_{0} \in(0,1)$ which solves equation (1).

By lemma 2, it is no longer guaranteed that a coalition of the rich among the nondominant groups and most members of the dominant group is feasible to overturn $s_{G}$

\footnotetext{
${ }^{18}$ If there are multiple solutions, we choose the smallest.

${ }^{19}$ In particular, a translation of $F($.$) to the right makes this possibility more likely.$
} 
when the marginal cost of discrimination to the non-dominant groups is sufficiently high. In such a scenario, the feasible option is to target just the dominant group with $E$. Thus, it is now possible to set $t=t^{\lambda}$ as the support of the rich from the non-dominant ethnic groups is no longer sought. Note, that the condition for such a strategy to succeed against $s_{G}$ is $\lambda V\left(t^{\lambda}\right) \geq \frac{1}{2}$.

We define $\lambda_{1}$ as inf $\left\{\lambda: \lambda V\left(t^{\lambda}\right) \geq \frac{1}{2}\right\}$. Clearly, $\lambda_{1}>\frac{1}{2}$ as $V\left(t^{\lambda}\right)<1$ since $f>0$ everywhere on $\mathbb{R}$.

We can now state that $\hat{\lambda} \equiv \min \left\{\lambda_{0}, \lambda_{1}\right\}$ provided $\lambda_{0}$ exists as a solution to equation (1).

We do not provide a detailed treatment of the $(\hat{\lambda}, \bar{\lambda})$ interval as there are no clear general results. ${ }^{20}$ However, it is clear from the preceding discussion that $s_{G}$ is not offered as an equilibrium platform. Hence, the (expected) amount of $G$ provided in any equilibrium in this $(\hat{\lambda}, \bar{\lambda})$ interval is lower than that under $s_{G}$, i.e., $\bar{y}$.

The findings above are collected together in the following proposition.

Proposition 1. In a democracy, the relationship between ethnic dominance (as captured by the magnitude of $\lambda$ ) and the share of the pure public good $G$ (or alternatively, the ethnic-specific public good $E$ ) provided in equilibrium takes the following form:

(i) There is a unique value of $\lambda$ - namely, $\hat{\lambda}$ - such that for all $0<\lambda \leq \hat{\lambda}$ the unique equilibrium allocation involves a tax rate of unity and spending the entire budget on $G$.

(ii) It is possible that $\hat{\lambda}<\frac{1}{2}$.

(iii) There is a unique value of $\lambda$ - namely, $\bar{\lambda}$ - such that for all $\bar{\lambda} \leq \lambda<1$ the unique equilibrium allocation involves a tax rate of unity and spending the entire budget on the ethnic-specific public good E, provided that the poor are sufficiently numerous.

Proposition 1 suggests a monotonic relationship between the extent of discriminatory spending and the size of the dominant ethnic group, albeit in a very coarse sense as the intermediate interval does not offer a general result. It is worthwhile to assess this result in relation to Mukand and Rodrik (2015). They argue that the distinctive nature of liberal democracy is that it protects civil rights (equality before the law for minorities) in addition to property rights and political rights. Their very definition of civil rights incorporates non-discrimination in the provision of public goods such as justice, security, education and health. Therefore, a good like $E$ cannot find legitimisation in a liberal democracy. So our framework should be considered as solely an electoral democracy. If and when the equilibrium policy involves providing no $E$ (like in the case of $(0, \hat{\lambda}]$ interval), does this assume the semblance of a liberal democracy.

\footnotetext{
${ }^{20}$ The details are available from the authors upon request.
} 
Next we move on to a similar analysis when instead of an electoral democracy, we have a dictatorship in place.

\subsection{Dictatorship}

In a dictatorship, there will be no explicit role for any political parties. The decision regarding the tax rate on incomes and the allocation of the resulting funds for providing $G$ and $E$ will be taken by the dictator, whom we shall refer to as $D$.

The other elements of the model remain just as before. We have our dominant ethnic group of size $\lambda$ and it will be assumed that the citizens have no direct control over the size or the allocation of the budget (just as before). In a democratic setup, the policies proposed by the two parties were governed by considerations of support by the citizens through the ballot. Here, under a dictatorial regime, certain different considerations will impel the dictator $D$ to raise taxes and allocate spending in a particular way.

There are some basic factors which any dictator must take into account. First, there is always a threat of a mass revolution. Hence, our dictator $D$ knows that with some chance he will not be ruling the roost in the near future. Secondly, staying in power is valuable to $D$; this provides access to "rents" which depend on the public budget. ${ }^{21}$ For simplicity, we will assume the following: $D$ lives for one period during which there is a chance of a mass revolution and if he survives the revolution (or if there is none) then he can usurp a part of the public budget. In case $D$ is overthrown, he gets a zero payoff.

Now this brings us to the question of what determines the incidence and success of a revolution. We posit a simple two-stage game to capture the idea of a revolution. In the first stage, the dictator proposes an allocation $\left(t_{D}, g_{D}, e_{D}\right) \geq(0,0,0)$ and also his share $\mu$ of the budget. ${ }^{22}$ The allocation $\left(g_{D}, e_{D}\right)$ is subject to feasibility constraints. Therefore,

$$
g_{D}+\lambda e_{D} \leq(1-\mu) t_{D} \bar{y}
$$

In the second stage, the members of the different ethnic groups simultaneously decide whether or not to revolt against $D$. Formally, each citizen chooses an action from the set $\{R, N R\}$ where $R$ denotes revolt and $N R$ not revolt. This action is taken individually by each citizen - hence, no coordination issues - and is done after each $\lambda$-group citizen draws her realization of $\epsilon$ which is the stochastic component of the payoff from $E$. This means that the decision of revolting (or not) is made after she

\footnotetext{
${ }^{21}$ More on these "rents" shortly.

${ }^{22}$ Announcing $\left(t_{D}, g_{D}, e_{D}\right)$ is sufficient for the citizens to infer $\mu$.
} 


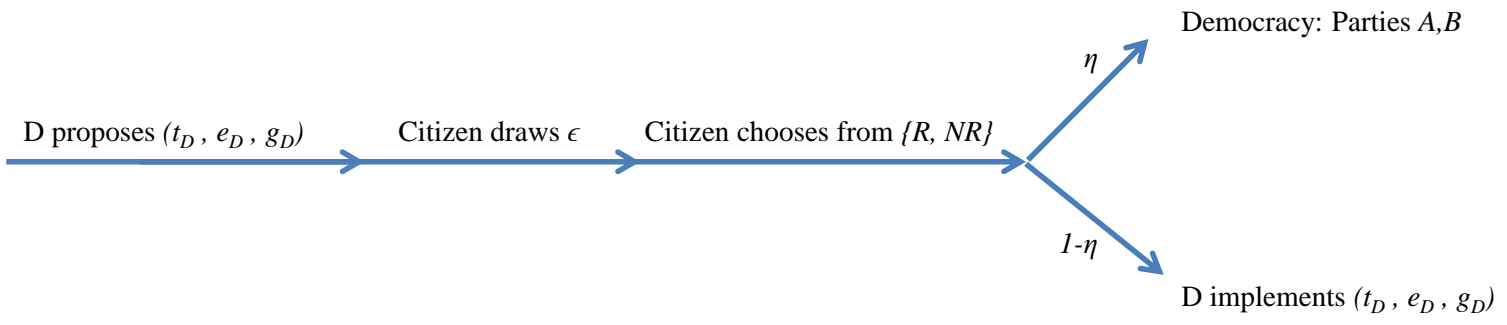

Figure 1: Timing. The sequence of moves under dictatorship.

knows her exact valuation of the $E$-good.

What happens when the revolt is successful and $D$ is deposed? We take the position that a two-party democracy emerges at the conclusion of a successful rebellion. The idea is that the political parties can be thought to remain dormant under a dictatorship, but emerge once the dictator loses power. In reality, in countries which move backand-forth between democracy and (military) dictatorships, prominent political parties are quite resilient and resume activities soon after the dictator is deposed (see e.g., the political histories of Pakistan and Zimbabwe among others).

At the end of the period, exactly one of the two things happen:

(i) all citizens choose $N R$ or some choose $R$ but the revolt is unsuccessful and $D$ implements his proposed $\left(t_{D}, g_{D}, e_{D}\right)$ and usurps $\mu$.

(ii) The revolt results in $D$ 's removal and democracy is restored. Under democracy, we have the citizens voting and deciding the tax rate and the allocation of the budget via the ballot. ${ }^{23}$

See Figure 1 for a graphical depiction of the timing.

Let $\eta$ denote the probability of a successful revolution. How does $\eta$ depend on the parameters of the model? We assume that larger the size of the rebel group, the higher is $\eta$. For the sake of concreteness, let $\eta$ equal the mass of people who choose action $R$. As a tie-breaking rule, we have that whenever a citizen is indifferent between $D^{\prime}$ s offer and the alternative equilibrium allocation under democracy, she chooses $N R$. This is easily justified by assuming there is a fixed $\operatorname{cost} c \geq 0$ which is incurred by the citizen

\footnotetext{
${ }^{23}$ Given that the outcome of the revolution (if there is one) is probabilistic, it is not possible for the political parties to gain any further information on any of the individual citizens' realisations of $\epsilon$; note, they already know the distribution $F($.$) of these \epsilon$ variables. Hence the possibility of any type of Bayesian updating does not exist in this setup.
} 
in case she chooses to rebel. In fact, we could explicitly incorporate this (private) cost of revolution $c>0$ into our model. However, we refrain from doing so as it complicates notation without adding any further insights; all our qualitative results are unchanged as long as $c$ is sufficiently low. In principle, $D$ can set $\mu$ equal to unity. That implies both $g_{D}$ and $e_{D}$ equal 0 .

We solve this two-stage game backwards, as is standard practice.

In the second and final stage, each citizen chooses an action from the set $\{R, N R\}$ based on $\left(t_{D}, g_{D}, e_{D}\right)$ and the expected payoff under democracy. If the expected payoff from democracy is no higher than under $D$ 's policy, then the citizen chooses $N R$; otherwise $R$ is chosen. This determines $\eta$, i.e., the success probability of the rebellion, as a function of $\left(t_{D}, g_{D}, e_{D}\right)$.

Taking this into account, $D^{\prime}$ s problem in the first stage is the following:

$$
\begin{aligned}
& \max _{\left(t_{D}, g_{D}, e_{D}, \mu\right)}(1-\eta) \mu t_{D} \bar{y} \\
& \text { s.t. } g_{D}+e_{D} \lambda \leq(1-\mu) t_{D} \bar{y}
\end{aligned}
$$

where $t_{D}, \mu \in[0,1]$ and $g_{D}, e_{D} \geq 0$. Notice, that the optimal choice of $\left(t_{D}, g_{D}, e_{D}, \mu\right)$ depends upon the degree of ethnic diversity $\lambda$, not just through the budget constraint but also by means of $\eta$.

Take any given $\lambda \in[0,1)$. What the citizens can expect to transpire in democracy will depend on where $\lambda$ stands in relation to $\hat{\lambda}$ (see Proposition 1). Recall the lower cutoff value of $\lambda$, namely $\hat{\lambda}$, from the democratic setup.

We start with $\lambda \leq \hat{\lambda}$.

Case 1: $\lambda \leq \hat{\lambda}$.

Recall, the unique equilibrium allocation under democracy involves delivering $s_{G}$ which implies the maximum feasible provision of $G$. This results in every citizen obtaining a payoff of $\bar{y}$ under democracy.

Suppose $D$ chooses to bank on the support of just the rich citizens. This means $t_{D}$ will need to be lower than 1 . First consider, the case when $D$ decides to provide $g_{D} \geq 0$ and $e_{D}=0$. Note, he needs to ensure that

$$
\left(1-t_{D}\right) y^{r}+(1-\mu) t_{D} \bar{y} \geq \bar{y}
$$

to get all the rich citizens to choose $N R$. Given that $\mu \leq 1$, the above implies

$$
\frac{1-t_{D}}{t_{D}} \leq \frac{\bar{y}}{y^{r}-\bar{y}}
$$


Hence, $D$ chooses $t_{D}$ to maximise $(1-\eta) \mu t_{D} \bar{y}$ where $\eta$ is simply the mass of the poor, i.e., $\pi$. Given the constraint above, $\mu t_{D} \bar{y}$ reduces to $\left(1-t_{D}\right)\left(y^{r}-\bar{y}\right)$ since $D$ will make the rich's constraint binding. Thus, $D$ 's objective function becomes $\left(1-t_{D}\right)\left(y^{r}-\bar{y}\right)$.

Notice, the above constraint for the rich to choose $N R$ has that the LHS is falling in $t_{D}$. Hence, the optimal choice of $t_{D}$ must be where

$$
\frac{1-t_{D}}{t_{D}}=\frac{\bar{y}}{y^{r}-\bar{y}}
$$

This, in turn, implies that $D$ sets $\mu=1$ and $t_{D}=\frac{y^{r}-\bar{y}}{y^{r}}$. Therefore, $D$ 's payoff is given by

$$
(1-\pi) \bar{y}\left(\frac{y^{r}-\bar{y}}{y^{r}}\right)
$$

Alternatively, $D$ could try enlisting the support of the $\lambda$ group by providing some amount of $E$ and some $t_{D} \leq 1$. This may dominate the strategy of targetting only the rich, if the proportion of the poor in the $\lambda$ group is sufficiently high. The following observation states this explicitly.

Observation 3. For $\lambda \leq \hat{\lambda}$, the dictator $D$ will offer to provide a positive of amount of only $E$ provided $\pi$ is sufficiently high. Otherwise, $D$ chooses $t_{D}=\frac{y^{r}-\bar{y}}{y^{r}}(<1)$ and sets $g_{D}=e_{D}=0$.

It would be useful, at this point, to contrast the asymmetry with the corresponding scenario under democracy - see Observation 1. While democracy guarantees the maximum possible provision of $G$, there is none provided under a dictatorship. If anything at all, the dictator provides $E$. This stark difference stems from the following: under democracy, the $(p, 1-\lambda)$ group is large enough to completely direct the allocation towards their bliss point. The dictator realises this and knows that this group cannot be deterred from rebelling, unless $D$ implements the democratic equilibrium policy this $D$ will not do since it entails a payoff of zero for him. Hence, $D$ tries to either assuage all the rich by cutting down on the tax rate - with no provision of $G$ or $E$ - or tries to win the backing of the majority of the $\lambda$ group (possibly along with the $(r, 1-\lambda)$ group) by offering them a positive level of $E$.

We now turn to the next scenario where $\lambda$ exceeds $\bar{\lambda}$.

Case 2: $\lambda \in[\bar{\lambda}, 1)$.

Under democracy, this $\lambda$ - interval is actually characterised by different payoffs to the different sub-groups. Recall, democracy here yields $s_{E}$ provided that $\pi$ is sufficiently high. This clearly complicates the analysis to some extent as the various sub-groups have different inclinations to rebel. 
Any member $i$ of the dominant ethnic group gets $\frac{\bar{y}}{\lambda}\left(1+\epsilon_{i}\right)$ from $s_{E}$. The payoff to any member of the minority section is $-\psi \frac{\bar{y}}{\lambda}$.

Clearly, it is the minority who has the least incentive to rebel. This is something the dictator will factor in while proposing his policy. In what follows, we will examine the set of feasible policies which $D$ may implement given the parameters $\left(\lambda, \pi, \psi, y^{p}\right.$ and $y^{r}$ ) when $\lambda \in[\bar{\lambda}, 1)$. We label them as P.1e, P.1g, and P.2 - it is useful to think of each of these categories as a set of policies, out of which $D$ will pick an optimal one. It is clear that, in equilibrium, $D$ will always choose $\mu>0$, i.e., steal a part of the tax revenues; otherwise, $D$ is guaranteed a payoff of zero with certainty.

P.1e: D sets $t_{D}<1$ with $e_{D}<\bar{y} / \lambda$ and $g_{D}=0$.

If $D$ chooses P.1e, then the entire $(1-\lambda)$ group will not rebel since both the tax rate and the level of $E$ (hence, discrimination) proposed by $D$ is lower than under democracy.

A member $i$ of the $\lambda$ group from income strata $j$ (i.e., $j \in\{p, r\}$ ) faces a genuine trade-off. Note, such a person will not rebel iff

$$
\left(1-t_{D}\right) y^{j}+(1-\mu) \frac{t_{D} \bar{y}}{\lambda}\left(1+\epsilon_{i}\right) \geq \frac{\bar{y}}{\lambda}\left(1+\epsilon_{i}\right)
$$

in other words, iff

$$
\epsilon_{i} \leq \frac{\lambda\left(1-t_{D}\right) y^{j}}{\bar{y}\left[1-t_{D}(1-\mu)\right]}-1
$$

So the mass of rebels is given by

$$
\eta=\lambda\left\{(1-\pi)\left[1-F\left(\frac{\lambda\left(1-t_{D}\right) y^{r}}{\bar{y}\left[1-t_{D}(1-\mu)\right]}-1\right)\right]+\pi\left[1-F\left(\frac{\lambda\left(1-t_{D}\right) y^{p}}{\bar{y}\left[1-t_{D}(1-\mu)\right]}-1\right)\right]\right\} .
$$

Hence, $D$ chooses $t_{D} \in(0,1]$ and $\mu \in[0,1]$ in order to maximise $\mu t_{D} \bar{y}(1-\eta)$ where $\eta$ is specified above.

What if $D$ proposed the same $t_{D}$ and $\mu$ but instead of providing $E$ simply switched to providing $G$ ? Can this yield a higher payoff? Such considerations bring us to the next feasible set of policies for $D$, namely, P.1g.

P.1g: D sets $t_{D}<1$ with $e_{D}=0$ and $g_{D}>0$.

We now examine the question posed above by looking at each of the different societal groups in turn. Notice, like in the case of P.1e, the entire $(1-\lambda)$ group will not rebel. In fact, their payoff under P.1g is strictly higher than under P.1e where their optimal action was to not rebel.

Like under P.1e, here too a member $i$ of the $\lambda$ group from income strata $j$ (i.e., $j \in$ 
$\{p, r\})$ faces a genuine trade-off. Thus, such a person will not rebel iff

$$
\left(1-t_{D}\right) y^{j}+(1-\mu) t_{D} \bar{y} \geq \frac{\bar{y}}{\lambda}\left(1+\epsilon_{i}\right)
$$

in other words, iff

$$
\epsilon_{i} \leq \frac{\lambda\left[\left(1-t_{D}\right) y^{j}+t_{D}(1-\mu) \bar{y}\right]}{\bar{y}}-1 .
$$

So the mass of rebels is given by

$$
\begin{aligned}
\eta=\lambda\left\{(1-\pi)\left[1-F\left(\frac{\lambda\left[\left(1-t_{D}\right) y^{r}+t_{D}(1-\mu) \bar{y}\right]}{\bar{y}}-1\right)\right]+\right. \\
\left.\pi\left[1-F\left(\frac{\lambda\left[\left(1-t_{D}\right) y^{p}+t_{D}(1-\mu) \bar{y}\right]}{\bar{y}}-1\right)\right]\right\} .
\end{aligned}
$$

If this is lower than the corresponding one under P.1e, then P.1e cannot be an optimal strategy for $D$. This is the subject of the following observation.

ObSeRvation 4. For $\lambda \in[\bar{\lambda}, 1)$, the dictator $D$ will prefer to provide a positive of amount of only $G$ rather than only $E$ provided the level of income inequality is lower than a certain level. Specifically, when $\theta \equiv y^{r} / y^{p}>1$ is below a threshold, D's payoff from P.1g exceeds that from P.1e.

The result in Observation 4 links the ambient level of income disparity to the provision of $G$ versus $E$ within the two sets of policies - P.1e and P.1g. In fact, as long as income inequality is not very extreme, $D$ prefers providing $G$ rather than $E$.

As argued in the proof of Observation 4, the comparison is made between P.1e and P.1g by keeping the same tax rate and $\mu$ and switching between $E$ and $G$. The key idea is to check for which of these two policies the mass of rebels is lower and hence the expected payoff is higher.

We identify the "indifferent" person - i.e., the threshold $N R$-choosing citizen - from the dominant ethnicity within each income group under P.1e. Then we compute the equivalent thresholds under P.1g for the same tax rate and $\mu$. For the poor citizens of the $\lambda$ group, this threshold comparison yields that the mass which prefers P.1g to the democratic policy is larger than the one which prefers P.1e to the democracy outcome. In other words, there is lesser opposition to $D$ from the poor among the $\lambda$ group if he picks P.1g rather than P.1e. The intuition for this can be found in the difference in the roles the taste heterogeneity element - i.e., $\epsilon$ - plays in P.1e and P.1g. For P.1g, the payoff under democracy depends upon the realisation of $\epsilon$ while the payoff from P.1g is independent of it. This is markedly different from the case of P.1e where the 
realisation of $\epsilon$ matters twice - once for the payoff under democracy and the second time for the the payoff from P.1e. Given that by construction the provision of $E$ is lower under P.1e than under democracy, this effectively implies that the realisation of $\epsilon$ must be sufficiently low for this poor individual from the $\lambda$ group to prefer P.1e to the democracy outcome. Such a stringent requirement does not apply to P.1g as the payoff under P.1g is independent of the realisation of $\epsilon$.

The analogous exercise for the rich among the dominant ethnic group does not yield such a clear outcome. In other words, the mass from the $(r, \lambda)$ group which prefers P.1g to the democratic policy cannot be unambiguously ranked vis-a-vis the one which prefers P.1e to the democracy outcome. However, as long as the income disparity is not too severe, the former will exceed the latter like in the case of the $(p, \lambda)$ group. To see why, note that the threshold in either P.1e or P1.g depends upon the income level of the individual. Moreover, the higher the income level the higher the threshold, with the jump being more pronounced in the case of P.1e. Thus, one cannot ensure that the ranking of thresholds in the poor group's case would be preserved here. For that to transpire, it must be that $y^{r} / y^{p}$ is not too high.

In sum, the mass of rebels is smaller under P.1g as compared to P.1e for the same level of expropriation by the dictator, provided that $y^{r} / y^{p}$ is below a certain threshold. Hence, it is more profitable for the dictator to pick P.1g over P.1e under such circumstances.

Next, we consider feasible policies for $D$ which involve setting a tax rate of unity as under democracy.

P.2: $D$ sets $t_{D}=1$ and $\mu>0$.

Here $D$ may choose between three options:

Case $(\mathrm{a}): \mu=1$;

Case (b) $\mu \in(0,1)$ and $g_{D}=(1-\mu) \bar{y}$; and

Case (c) $\mu \in(0,1)$ and $e_{D}=\frac{(1-\mu) \bar{y}}{\lambda}$.

We will examine each, in turn, to determine which yields $D$ the highest expected payoff given the strategy of the citizens in last stage.

Case (a): If $t_{D}=\mu=1$, then the non-dominant ethnic groups do not rebel. A member of the $\lambda$ group will choose $N R$ iff $\frac{\bar{y}}{\lambda}\left(1+\epsilon_{i}\right) \leq 0$. In other words, any member of the $\lambda$ group will choose $N R$ with a probability of $F(-1)$.

Thus, the mass of rebels is given by $\lambda[1-F(-1)]$ and $D$ 's payoff is

$$
\bar{y}[1-\lambda(1-F(-1))]
$$


Case (b): When $\mu \in(0,1)$ and $g_{D}=(1-\mu) \bar{y}$, the non-dominant ethnic groups do not rebel. A member of the $\lambda$ group will choose $N R$ iff

$$
(1-\mu) \bar{y} \geq \frac{\bar{y}}{\lambda}\left(1+\epsilon_{i}\right)
$$

So, any member of the $\lambda$ group will choose $N R$ with a probability of $F(\lambda(1-\mu)-1)$. Hence, the mass of rebels is given by $\lambda[1-F(\lambda(1-\mu)-1)]$ and $D$ 's payoff is

$$
\mu \bar{y}[1-\lambda[1-F(\lambda(1-\mu)-1)]] .
$$

Case (c): When $\mu \in(0,1)$ and $e_{D}=\frac{(1-\mu) \bar{y}}{\lambda}$, the non-dominant ethnic groups do not rebel. A member of the $\lambda$ group will choose $N R$ iff

$$
\frac{\bar{y}}{\lambda}\left(1+\epsilon_{i}\right) \leq \frac{(1-\mu) \bar{y}}{\lambda}\left(1+\epsilon_{i}\right) .
$$

In other words, any member of the $\lambda$ group will choose $N R$ with a probability of $F(-1)$. Thus, the mass of rebels is given by $\lambda[1-F(-1)]$ and $D$ 's payoff is

$$
\mu \bar{y}[1-\lambda(1-F(-1))]
$$

Case (c) is clearly dominated by Case (a) as evidenced from eye-balling the expected payoff to $D$ in both cases. The comparison between Cases (a) and (b) is less straightforward as the following lemma informs.

LEMMA 3. Under certain parametric restrictions in the case of $\lambda \in[\bar{\lambda}, 1), D$ can obtain a higher payoff from setting $\mu \in(0,1)$ and $g_{D}=(1-\mu) \bar{y}$ than from $\mu=1$.

In light of Observation 4, a comparison across the different payoffs confronting the dictator is now ready to be presented. It turns out that there is a general indeterminacy as regards to which course of action is optimal from the dictator's perspective. Clearly, as long as the level of inequality is not very extreme, $D$ should not provide any $E$ but whether he will provide a positive amount of $G$ or simply nothing is indeterminate (see Lemma 3 above). This is summarised in the following observation.

OBSERVATION 5. For $\lambda \in[\bar{\lambda}, 1)$, the dictator $D$ will promise either a positive of amount of only $G$ or nothing provided the level of income inequality is lower than a certain threshold (identified in Observation 4).

On the whole, it is the case that for $\lambda \in[\bar{\lambda}, 1)$, there is lower discrimination under $D$ as compared to under democracy. To be sure, if the level of inequality is sufficiently high 
so that the dictator actually chooses P.1e over P.1g, it still means that discrimination is lower under here than under democracy. Notice that the effect is not purely mechanical - i.e., $D$ pilfers a fraction $\mu$ and hence the provision $E$ is lower - but strategic in the sense that $D$ actually chooses to impose a lower tax rate $\left(t_{D}<1\right.$ under P.1e) and hence deliberately discriminates less.

The core message of the analysis of the dictatorship regime from Observations 3 through 5 is summarised and collected in the following proposition.

Proposition 2. In a dictatorship, the relationship between ethnic dominance (as captured by the magnitude of $\lambda$ ) and the share of the pure public good $G$ offered by the dictator in equilibrium takes the following form:

(i) For $\lambda \in(0, \hat{\lambda}]$, the equilibrium allocation involves the dictator offering only $E$ provided the poor are numerous enough; otherwise $D$ sets $\mu>0$ and offers nothing.

(ii) For $\lambda \in[\bar{\lambda}, 1)$, either $G$ or nothing may be offered in equilibrium provided the level of income inequality is below a threshold. If the income inequality is sufficiently high, then $D$ may offer E. However, the level of $E$ offered is lower than under democracy since $t_{D}<1$ and $\mu>0$.

We would like to draw attention to the proposition above and contrast it with our main result for the case of the democratic setup, namely, Proposition 1. Recall that in our democratic setup (with the standard two-party competition framework), we obtained that for a highly ethnically heterogeneous society (i.e. $\lambda$ "small"), the entire budget will be spent on providing $G$ - hence, no discrimination. On the other hand, we find that for a dictatorship a highly ethnically heterogeneous society will see a provision of only the $E$ good (or nothing) - therefore, some potential discrimination. A similar contrast appears when considering an ethnically homogeneous society (i.e., $\lambda$ close to 1). Under democracy, such a society would see the maximum possible provision of the $E$ good; hence, the highest possible discrimination. In a dictatorship, the pattern is very different - in particular, $G$ might be offered. Even if there is some provision of $E$, the dictator will strategically choose a smaller amount than what is offered under democracy by setting $t_{D}<1$. What is striking is the reversal in the pattern of spending under a dictatorship as compared to that in a democracy in the $(0, \hat{\lambda}]$ and $[\bar{\lambda}, 1)$ intervals.

The core results contained in the two propositions have been collected in Table 1. A quick perusal of the table makes apparent the reversal in the pattern of spending across the two regimes for the different levels of ethnic dominance. 


\begin{tabular}{|c|c|c|}
\hline $\begin{array}{l}\text { Ethnic Dominance } \\
\qquad(\lambda)\end{array}$ & $\begin{array}{l}\text { Equilibrium Outcome(s) } \\
\text { Under Democracy }\end{array}$ & $\begin{array}{l}\text { Equilibrium Outcome(s) } \\
\text { Under Dictatorship }\end{array}$ \\
\hline$\lambda \in(0, \hat{\lambda}]$ & $t=1, g=\bar{y}, e=0$ & $\begin{array}{l}t \in(0,1], g=0, e>0 \\
\text { for } \pi \text { sufficiently high } \\
\qquad \text { OR } \\
t \in(0,1), g=e=0\end{array}$ \\
\hline$\lambda \in[\bar{\lambda}, 1)$ & $\begin{array}{c}t=1, g=0, e=\bar{y} / \lambda \\
\text { for } \pi \text { sufficiently high }\end{array}$ & $\begin{array}{c}t \in(0,1], g \geq 0, e=0 \text { for } \frac{y^{r}}{y^{p}} \\
\text { below a threshold } \\
\text { OR } \\
t \in(0,1), g=0, e \in(0, \bar{y} / \lambda)\end{array}$ \\
\hline
\end{tabular}

Table 1: Summary of the Main Results.

\subsubsection{The identity of the dictator}

We have treated the dictator as an independent entity, not personally identifying with any of the $N$ ethnic groups or the income classes (poor or rich). What the dictator is solely concerned with is his expected payoffs from holding on to the reins of power which arise from appropriation of the revenues raised through taxation. In practice, a dictator often relies on the support from the military (examples of such cases are plenty - consider Pakistan, Indonesia, Rwanda among others).

Acemoglu and Robinson (2006) point to the incentives of the elite to support such nonrepresentative governments. Acemoglu, Ticchi and Vindigni (2010) explicitly model the military as a distinct group who acts in its self-interest. Our notion of a dictator is essentially as the representative agent of this group. This is quite different from the setup in Padro-i-Miquel (2007) where the ethnic identity of the dictator is crucial in driving the logic of rent extraction from society, and in particular, from the ruler's co-ethnics.

In a similar vein, we model political parties as voteshare-maximising and without affiliations/biases vis-a-vis the different ethnic groups, in the tradition of Hotelling models of political competition.

The political actors (i.e., the dictator and the political parties) are deliberately kept neutral in terms of ethnic identities. This is done partly in the interest of simplicity. There is another justification for this - we believe that by "switching off" this 
ethnic alignment channel we are able to highlight a specific mechanism linking public spending to regime changes. Our contention is that the cases we highlight in Section 5 can be more comprehensively understood using our mechanism rather than the ethnic alignment perspective. In that section, we argue that ethnic alignment with the leader alone cannot sufficiently explain the nuanced patterns of the treatment of the minorities in the various cases. ${ }^{24}$

\subsubsection{Expropriation under dictatorship}

When the dominant ethnic group is "small" (i.e., $\lambda \leq \hat{\lambda}$ ), the dictator's policy is particularly inimical to the minorities, particularly, the poor among them. This is due to the following: (i) no $G$ is provided in contrast with the scenario under democracy, and (ii) if anything some $E$ is provided with tax rates lower than under democracy. Hence, the dictator's policy here reflect - in a way - the idea of the "tyranny of the majority".

When the size of the dominant ethnic group is in excess of $\bar{\lambda}$, democracy clearly favours the ethnic majority. Under dictatorship, the equilibrium policy in this scenario is less discriminatory (less $E$, if any); however, it is worthwhile to point out that the expropriation by the dictator may well lead to substantially lower societal welfare from a utilitarian perspective.

On the whole, our analysis clearly reveals that dictatorships are associated with lower public spending - be it discriminatory or otherwise - and thus under-perform in terms of social welfare when compared with democracy.

\subsubsection{The payoffs to the different ethnic groups}

The main thrust of the analysis has been on identifying the extent of discrimination, through the provision of $E$ at the cost of $G$, under the different regimes. However, the analysis does identify some gainers and losers under the two regimes for any given level of ethnic dominance. Here, we discuss briefly as to which groups fare better under dictatorship for the different possible levels of $\lambda$.

First, we will compare the dominant ethnic group with the rest taken together. Then, we shall discuss the case where $N>2$ and compare across different minority groups.

When the size of the dominant ethnic group is "small" (i.e., $\lambda \leq \hat{\lambda}$ ), democracy delivers complete redistribution; hence, every citizen regardless of income level or ethnic identity

\footnotetext{
${ }^{24}$ We are grateful to an anonymous referee for highlighting this issue.
} 
gets the same payoff $(\bar{y})$. Under a dictatorship for this $\lambda$ interval, there is a clear heterogeneity in payoffs. Exactly one of the two things happen: (1) $D$ caters to the rich irrespective of ethnic identity (by leaving them with a payoff of $\bar{y}$ ) and providing the poor with a payoff strictly lower than $\bar{y}$ and (2) $D$ provides a positive level of $E$ (and no $G$ ) and hence leaves the dominant ethnic group in each income category happier than the others in the corresponding income category. In particular, a section of the rich among the dominant ethnic group get a payoff greater than $\bar{y}$. Thus, $D$ may well have the support of the ethnic majority group - particularly, the rich among them - whenever $\lambda \leq \hat{\lambda}$.

When the size of the dominant ethnic group is in excess of $\bar{\lambda}$, democracy tends to favour the ethnic majority. Under a dictatorship for this $\lambda$ interval, there is again a heterogeneity in payoffs. Here, $D$ may provide a positive level of $G$ and will certainly provide lesser of $E$ for a range of $\lambda$ beyond $\bar{\lambda}$. Since discrimination is unambiguously lower here under dictatorship, the disparities in payoffs across the different minority groups is smaller.

Now consider two different minority groups - call them groups 2 and 3 (where the dominant ethnic group is labelled ' 1 '). Without loss of generality, let us say that group 2 is richer than group 3. In light of our analysis above, what can one infer regarding the payoffs to these two minority groups?

When $\lambda \leq \hat{\lambda}$, democracy delivers equally to all ethnic groups. However, under dictatorship things have the potential to look different. In the situation where $D$ exclusively caters to the rich (irrespective of ethnic identity) by setting taxes lower than under democracy, it is group 2 which stands to gain relative to group 1 . In case $D$ chooses to provide some $E$ (and no $G$ ), both groups 2 and 3 feel the brunt of discrimination. However, even here group 2 is better off than group 3 since $t_{D} \leq 1$ with the inequality being strict for certain parameter values. In sum, the richer minority group is always better off in comparison with the poorer ones (at least weakly) under dictatorship as long the dominant group is not too large.

When $\lambda$ exceeds $\bar{\lambda}$, democracy tends to favour the ethnic majority at the cost of the other groups. Hence, both groups 2 and 3 are equally penalised under democracy. Under a dictatorship, it may transpire that $t_{D}<1$ so that group 2 is better off than group 3.

On the whole, it appears that the dictatorship is relatively more benevolent towards the rich minorities; although, this is merely a reflection of the fact that the dictator tries to win the approbation of the rich in general. 


\section{Some Extensions}

Here we discuss some implications of extending our model in certain directions.

\subsection{Heterogeneity in the disutility from discrimination}

In the baseline model, we allow for heterogeneity in the preference for the ethnic good $E$ among the members of the dominant group. In a similar vein, one could introduce heterogeneity in the disutility from discrimination (i.e., provision of $E$ ) for the other members of society. This is what we explore here. Hence, we let $\psi$ vary across the individuals from the non-dominant groups. Let $\psi_{i}$ for any such individual $i$ be drawn from a distribution $M_{j}($.$) which is defined on (0,1)$ for $j \in(p, r)$. Thus, we are allowing the two distinct income groups to have different distributions from which the disutility from discrimination parameter is drawn. ${ }^{25}$

We now analyse the democracy case with this structure in place. Observation 1 applies without qualification in this context. The idea that both parties will propose to spend the tax revenue on the general public good as long as the size of the dominant ethnic group is below a threshold is robust to such heterogeneity in the disutility from discrimination. To be sure, the quantitative value of this threshold $(\hat{\lambda})$ is dependent on the specifics of the distributions $M_{p}($.$) and M_{r}($.$) ; however, the core result still applies. To$ see how the distribution of $\psi_{i}$ affects $\hat{\lambda}$, observe that $M_{r}($.$) determines the tax rate(s)$ which the rich from the non-dominant groups find acceptable to support a platform involving discrimination against one involving pure redistribution (i.e., $s_{G}$ ). Hence, this will determine the exact value of $\lambda_{0}$ which represents the size of the $\lambda$ group where support against $s_{G}$ is exactly $1 / 2$ (so, a tie). Finally, the exact value of $\lambda_{0}$ determines the threshold $\hat{\lambda}$.

Observation 2 also retains validity here. The key idea mooted in this observation is the existence of a (minimum) threshold for the size of the dominant ethnic group such that the proposal to spend the entire tax revenue on the ethnic good alone becomes a winning strategy for any political party. As long as $\psi_{i}$ is positive for individuals from the nondominant groups, this idea prevails. A perusal of the proof of this observation reveals the value of the threshold $\bar{\lambda}$ does not depend upon the specifics of the distributions $M_{p}($.$) and M_{r}($.$) . The necessary requirement is that \psi_{i}>0$ for any individual $i$ belonging to a non-dominant group.

As Observations 1 and 2 form the basis of Proposition 1, we can infer that nothing of substance is altered in this new environment for the democracy scenario.

\footnotetext{
${ }^{25}$ The distributions, of course, need not be distinct. This has no significant bearing on our results.
} 
Moving on to the case of dictatorship, we note that Observation 3 is unaffected by the new structure on $\psi_{i}$. As long as $\psi_{i}$ is non-negative for individuals from the nondominant groups, the proof of this result is unaltered. Observation 4 concerns a comparison of two policies in both of which the non-dominant groups do not rebel as long as $\psi_{i}$ is non-negative for them. Hence, the specifics of $M_{p}($.$) and M_{r}($.$) have no bearing$ upon this result. Establishing Lemma 3 and hence Observation 5 relies on assuming $\psi_{i}$ is non-negative for individuals from the non-dominant groups, but not anything specific about the distribution of $\psi_{i}$. Therefore, Proposition 2 - which stands on Observations 3 through 5 - remains valid with the assumption of heterogeneity in the disutility from discrimination. In sum, we conclude that the core results survive with this added feature.

\subsection{Increased role of dictatorship}

In our setup, while it is possible to have a transition from dictatorship to democracy (via a successful revolt) we do not allow for a transition to another dictatorship. It is fair to argue that any dictator may be worried about democratic revolutions in no less measure than coups by other dictators. In a similar vein, one might ask how the results change if we somehow allow for transitions from democracy to dictatorship than just the other way round.

We discuss the implications of such considerations below.

\subsubsection{Dictatorship resulting in (another) dictatorship}

Suppose we allow for the possibility that the outcome of a successful revolt against the dictator $D$ is a lottery between democracy and dictatorship under an alternative leader $D^{\prime}$. For simplicity, assume that the odds of this lottery are exogenous. To what extent will it affect our central findings?

To keep things tractable, we assume that the citizens view $D$ and $D^{\prime}$ in the same manner. In other words, their expectation of public spending under $D^{\prime}$ is identical to what they expect from $D$. This is plausible if the citizens impute the same objective function to all potential dictators. Given this, the outcome of a successful revolt is

either democracy or the same as an unsuccessful revolt as both dictators would behave in the same manner when faced with the same policy-setting task.

From the perspective of each citizen, how does this affect the choice between revolting or not? Given that the outcome from a successful revolt is now a lottery between democracy and dictatorship (under $D^{\prime}$ ), the choice is still effectively the same - choose 
$N R$ if the payoff from democracy is less than or equal to that from dictatorship (be it under $D$ or $D^{\prime}$ ); otherwise, choose $R$. Therefore, every citizen's choice in the dictatorship scenario remains unaffected. Thus, one may claim that nothing of essence is altered by introducing the possibility of dictatorship lapsing into (another) dictatorship in this manner.

\subsubsection{Democracy to dictatorship}

We can modify the democracy game in the following manner. Suppose at the end of the election game, instead of the winning party assuming office and implementing its proposed policy, there is the possibility of a (military) coup by $D$. Further, suppose that this coup is successful with some given exogenous probability. How will this change the results of the democracy game? Observe that as long as either political party is unable to influence the probability of the coup (or its success), nothing effectively changes each party chooses its policy to maximise the chance of winning against the rival party just like in the baseline model.

Alternatively, assume that expropriation is allowed even under democracy but the more any political party aims to expropriate the higher is the chance of a successful coup by $D{ }^{26}$ In this situation, we will recover our baseline result of zero expropriation under democracy owing to the logic of a Bertrand duopoly-like competition among the two political parties. In other words, each political party would try to under-cut the other in terms of less expropriation and more public spending to get a jump in the probability of victory and simultaneously reduce the chances of a coup.

\subsection{An ethnic good for each ethnic group}

There is an important asymmetry in the baseline model - the dominant ethnic group is allowed directed spending aside from general public spending but the only benefit accruing to the minorities comes from general public spending. The reason behind this asymmetry was to precisely bring out the idea of discrimination as starkly (and as simply) as possible. However, it is possible to allow for a similar ethnic "good" for the minorities and yet retain the main results.

For the $N-1$ non-dominant groups, suppose there exists an ethnic good $E_{n}$ spending on which benefits only members from the ethnic group $n \in\{2, . ., N\}$. Also, let there be heterogeneity within each group as to the preference for this good in a manner

\footnotetext{
${ }^{26}$ The idea is that the more corrupt a democratic regime is, the lower is the aversion of the citizens' towards alternative regime structures.
} 
analogous to the dominant group's ethnic good $E$. So when $E_{n}$ is provided, more than half the minority group $n$ gets a positive realisation of the taste shock.

Before proceeding any further, it is important to clarify what "discrimination" means in this context. Clearly, when all the spending is on the general public good $G$, then there is no discrimination (like in the baseline model). However, when there is some spending on $E$, the entire minority feel discriminated against. Similarly, when there is some spending on some $E_{n}$, all the other groups who do not get any targeted spending feel discriminated against. So now, we ask the question as to how all such forms of discrimination fare under the different political regimes.

As before, first consider the situation under democracy. When the size of the dominant group is not too 'large' (similar to Observation 1), one can argue that only $G$ is provided. Now, the clear contender to this allocation is some combination of spending on $E$ and $E_{n}(n \in\{2, . ., N\})$. Notice however, that when spending is promised on all these ethnic goods, members from all groups without targeted spending feel discriminated and hence would simply prefer a platform with only general public spending (no discrimination). The logic in the case of high ethnic dominance (as in Observation 2) is unchanged from before - both parties will only cater to the dominant ethnic group when the latter is of a sufficient large size. Hence, the equilibrium allocations do not change under democracy.

Now moving over to the dictatorship scenario, we see that for low ethnic dominance (as in Observation 3) the dictator now has the option of using the $E_{n} \mathrm{~s}$ as a means to dissuading the minority groups from rebelling. However, the more he spends on the $E_{n} \mathrm{~s}$ the less he has for spending on $E$ and for his own consumption. Given that the minority groups have a particularly high incentive to rebel, it is too costly to provide $E_{n} \mathrm{~s}$ by cutting back on $E$. Moreover, spending (sufficiently) on the $E_{n}$ s at the cost of $E$ would mean that the dictator would lose some of the majority group citizens to gain a few minority votes (recall, the dominant ethnic group is the largest among the $N$ groups). This is clearly not optimal from the dictator's perspective. Thus, once again the dictator would use only $E$ in this situation. When ethnic dominance is high (as in Observations 4 and 5 ), the dictator will not spend on any $E_{n}$ since the minorities would not be rebelling for $\lambda$ beyond $\bar{\lambda}$.

In sum, it is possible to introduce this additional aspect of ethnic spending for the minorities without affecting the main findings in any significant manner. 


\section{Discussion}

In this section, we discuss some historical events which when analysed within the framework of our model appear to corroborate the model's predictions. In most of the following cases, there is a change in regime - from democracy to dictatorship or vice versa - and some degree of ethnic heterogeneity which allows us to make a comparison in terms of changes in (targeted) public policy. The implicit assumption is that the level of ethnic dominance for a country is largely unaffected by the regime change. Moreover, in each of these cases the democratic setup is effectively an electoral one and falls short of the requirements of a liberal democracy as shall be clear in the ensuing discussion.

We consider countries with both high and low ethnic dominance to illustrate the workings of our theory.

\subsection{Rwanda}

The Hutu community is the major ethnic group in Rwanda (over 80\%) and a dominant minority group is the Tutsi community (about 15\%). In 1962, Rwanda achieved independence from Belgian rule, and Gregoire Kayibanda, a Hutu, was elected the first president of the Rwandan Republic. Unfortunately, there was a deliberate widening of ethnic cleavages at the outset, and Tutsis became the victims of official discrimination in virtually all public services and in politics. ${ }^{27}$ In 1963, there was a massacre of Tutsis, in response to an ill-planned military attack by exiled Tutsis in Burundi, which provoked a Hutu backlash that claimed more than 10,000 Tutsi lives in a four-day period. Before such Tutsi incursions ceased, 20,000 of them had been killed, and another 300,000 had fled to the Congo, Burundi, Uganda, and Tanzania (then called Tanganyika). Not only were these Tutsi 'outsiders' despised, but Hutu government officials accused all Tutsi of being their accomplices and they were slaughtered indiscriminately, and that included women and children. ${ }^{28}$ Between 1963 to 1967, around 100,000 Tutsis were butchered with machetes and dumped in rivers, and in 1973, there was a purge of Tutsis from universities, and Tutsi students were massacred in thousands. Brandstetter (1997) contends that between 1959 and 1973, hundreds of thousands of Rwandans fled the country in the wake of the massacres and expulsions during the Rwandan 'revolution'. These refugees were almost exclusively Tutsi.

The wave of anti-Tutsi pogroms and the general atmosphere of intimidation and terror

\footnotetext{
${ }^{27}$ The system of ethnic identity cards differentiating Hutus from Tutsis was introduced by the Belgians in 1926.

${ }^{28}$ Rwanda: The Preventable Genocide (refworld.org)
} 
that led to yet another exodus of thousands of Tutsi from the homeland in the early seventies led to General Juvenal Habyarimana, the (Hutu) senior military officer, ultimately seizing power through a bloodless coup in July 1973, with a promise to restore order and national unity. The atmosphere of the country was so oppressive at that point that the coup was met with widespread popular relief, even by most Tutsi (see Prunier (1995)).

For years the Habyarimana regime, a military dictatorship, had rather a positive image in international circles, among international donors and development organisations. The general opinion was that the Rwandan government had solved the ethnic question successfully and dedicated itself to peace and development. During Kayibanda's time, the Tutsi were effectively banned from the upper reaches of the government and the military. Their sole opportunity for advancement was the all-important public sector, where jobs were made available to ethnic groups in proportion to their numbers. Under Habyarimana's rule, the Tutsi were not treated as equals, but life for them became much more tolerable. Habyarimana promised them a normal peaceful existence so long as they stayed away from politics, government, and the military. This implicit deal between Habyarimana and the Tutsis led dramatically to an end to the ethnic violence. Physical harassment largely ceased and, for 17 years, there were no massacres of the Tutsi populace.

Quite importantly, the private sector was opened up, and many Tutsis flourished in business, and largely dominated international trade. It was well known that some Tutsi entrepreneurs had developed cordial relations and some influence with Hutu government officials. While ethnic quotas remained the rule, they were now loosely enforced, and Tutsi were known to have considerably more than their allotted nine per cent of the places in schools, universities, the professions, and even the civil service. So, normal day-to-day life for Rwanda's Tutsis under Habyarimana's dictatorship was incomparably better than it had been under Kayibanda's 'democratic' regime. Most foreigners admired the regime uncritically and felt that Rwanda under Habyarimana came close to being a textbook case of an efficiently-run dictatorial government.

In the context of our model, the Rwandan situation describes a society which is fairly homogeneous in ethnicity and which sees a transition from democracy to dictatorship. ${ }^{29}$ By Propositions 1 and 2, such a society would be characterised by neglect of minorities under democracy and (relatively) equal treatment under dictatorship. The above account seems consistent with such predictions.

The political situation in post-genocide Rwanda has been described as a quasi-autocracy,

\footnotetext{
${ }^{29}$ Habyarimana created the Mouvement Revolutionaire National pour le Developpement (MRND) as the country's only legal party in 1975.
} 
given President Kagame's influence (see Blouin and Mukand (2019)). In terms of our theory, this ought to be a period characterised by equal treatment of the ethnic groups. Blouin and Mukand (2019) exploit variation in exposure to the government's radio propaganda due to the mountainous topography of Rwanda. Results of their lab-in-the-field experiments demonstrate that individuals exposed to government propaganda have lower salience of ethnicity, increased inter-ethnic trust and show more willingness to interact face-to-face with members of another ethnic group. Therefore, this government is improving relations between ethnic groups rather than engage in discrimination, which is consistent with our theory. While Kagame is a Tutsi and this per se may affect how the Tutsis in Rwanda are treated at present, there is no doubt that the regime change from Kayibanda to Habyarimana (both Hutu) had important repercussions for the conditions of Tutsis.

\subsection{Indonesia}

Indonesia is an ethnically diverse country where largest ethnic group is the Javanese, who comprise about $42 \%$ the population and are politically and culturally dominant (see e.g., Kingsbury (2003)). To judge the status of the Chinese-Indonesians, it is important to see how the relation between Indonesia and the People's Republic of China (PRC) evolved over the years. Under Sukarno's government, a cordial relationship existed between the two countries, generally. This bond severed completely when Suharto came to power (see Tan (2005)). The 1965 upheaval also involved the PRC government directly, when it sent ships for the ethnic Chinese who had become refugees. This included about 10,000 people in Medan and 350,000 in West Kalimantan. After 1967, the diplomatic relationship between Indonesia and the PRC was frozen and not officially resumed until 1990, although trade between the two nations resumed before that.

President Suharto's regime (also called the "New Order") lasted over 30 years (19661998) and can be safely classified as a non-democracy for most of its duration. In 1967, the New Order government created a committee to study what was called the 'Chinese problem' (see Purdey (2006)). The key issue was to profit from their economic aptitude whilst ridding them of any potential economic dominance. The New Order effectively instituted a system whereby the ruling class could take advantage of an economically skilled and successful ethnic minority which was highly susceptible to intimidation and plunder and was therefore reliant on the powers-that-be for protection. However, while urging ethnic Chinese to integrate with the others, the Suharto government enacted discriminatory regulations at the same time, such as a special citizenship document, putting a special code on the identity card, prohibiting the use of Chinese characters 
in public, and discouraging speaking Chinese in public. Although name changing was not compulsory, a great deal of moral pressure was applied to the Chinese population to change their names (see Tan (2005)).

In terms of our model, $E$ represents any type of systematic spending which is detrimental to the members of the minorities while benefiting (on average) the members of the dominant ethnic group. Notice, directed violence against a minority strikes fear in the hearts of other minorities. In fact, in the economic sphere this can be beneficial to the dominant ethnic group as they have to contend with less competition. ${ }^{30}$ This is evidence of a pattern of disfavouring minorities in a setup characterised by low ethnic dominance under a dictatorship (providing $E$ rather than $G$ in terms of our model as in Proposition 2).

In May 1998, there was a massive unrest in the country. Panggabean and Smith (2011) note that the process that led to Suharto's resignation was marked, among other things, by the full-blown ethnic anti-Chinese rioting in several parts of the country including Jakarta, Medan, and Solo. They explain why violence escalated in Medan and Solo, in particular, while the same did not happen in similar cities of Surabaya and Yogyakarta in terms of "a conscious tactic employed by state security forces" in the face of unmanageable student demonstrations that began to attract large mass followings off campuses. They also "took pre-existing mass mobilization against the regime and actively shifted its rhetorical and targeting frame to one focused on ethnic Chinese businessmen and their property", according to Panggabean and Smith (2011).

Jha (2018) makes the point that while the trading networks of the Chinese-Indonesians made them valuable to the local population, these groups lacked a general mechanism of redistribution. Chinese trading networks, based upon personal and community ties, were closed to competitors, which means that a relatively small ethnic minority were able to capture much of the gains from trade. This aspect appears to have rendered them increasingly attractive targets for ethnic violence and susceptible to expropriation by locals. Jha highlights a key incentive problem: what transfers do occur will be from rich non-locals to the (local) incumbent political elite, as the latter have the lowest costs of engaging in violence. As observed by Jha, "these transfers of protection money to rulers by non-local groups, sometimes called 'ethnic cronyism', may actually provide perverse incentives for rulers to intermittently allow ethnic violence by poorer locals in order to extract greater transfers from non-local minorities." Jha notes that these patterns fit the intolerance faced by commercially-oriented Chinese ethnic minorities in Suharto's Indonesia. This resonates with the idea of "appeasement of the rich" as noted in Observation 3 above.

\footnotetext{
${ }^{30}$ This argument is similar in spirit to various studies which document the dynamics of HinduMuslim violence in India (see Mitra and Ray (2014) among others).
} 
This pattern of persecution was abandoned - at least to an extent - after the transition to democracy in the 21st century. Tan (2005) observes: "Since the end of the repressive Suharto regime, aside from some localized incidents, the ethnic Chinese have been left more or less alone." After the fall of Suharto, numerous discriminative laws were recalled and others promoting unity were passed. President Habibie passed legislation requiring the elimination of the terms pribumi and non-pribumi (native Indonesian and non-native) in 1998. In 2002, Chinese New Year was declared a national holiday. However, some discriminative legislation still remains. Chinese Indonesians have been "embraced" by the government, with numerous mixed-ethnic cultural presentations and media activity. By 2004, there were three Chinese Indonesian members of the Peoples Representative Council, as well as one cabinet member. This is again in line with our result in Proposition 1 which states that democracies with low ethnic dominance do not discriminate in terms of public spending across ethnic groups (i.e., they provide $G$ rather than $E$ ).

\subsection{Myanmar}

Myanmar, formerly known as Burma, has witnessed serious political turnovers since its independence from the British in 1948. The first decade following independence was devoted to reconstruction which was necessary given the devastation caused to the region from the Second World War. However, this phase was somewhat politically turbulent. In March 1962, Ne Win led a military coup and arrested $\mathrm{U} \mathrm{Nu}$, the chief justice, and several cabinet ministers. He justified his actions as a means of keeping the union from disintegrating. Suspending the 1947 constitution, which had been in effect since independence, he ruled the country with a Revolutionary Council consisting of senior military officers.

Ne Win's stated purpose was to make Burma a truly socialist state. A militarycontrolled one-party (Burma Socialist Programme Party [BSPP]) system was established. In April 1972, Ne Win and other members of the Revolutionary Council retired from the army, but they retained their positions of power in the BSPP. Since the late 1980s, pro-democracy voices started gathering force. In May 1990, Myanmar held its first multiparty elections in 30 years. Myanmar saw a full-scale transition to democracy in 2015 where Aung San Suu Kyi's party won a landslide victory, taking 86\% of the seats in the Assembly of the Union. Although she was prohibited from becoming the President due to a clause in the constitution she assumed the newly created role of State Counsellor, making her the de facto head of government.

The persecution of Rohingya Muslims in Myanmar's Rakhine State can be traced back to the 1970s. They have suffered systematic human rights abuses at the hands of 
the Myanmar authorities, security forces, police, nationalist Buddhists, and the local Rakhine population who have engaged in widespread violence, acts of torture, arbitrary detention, rape, and other grievous crimes. The scale of these atrocities increased precipitously since 2012. The Rakhine Nationalities Development Party (RNDP), founded in 2010 by Rakhine nationalists, was one of the most influential groups in the spread of anti-Rohingya violence, particularly during and after 2012. The RNDP demanded that the government relocate displaced "non-Myanmar Bengali nationals" away from Rakhine neighbourhoods and, eventually, out of Myanmar entirely. On July 12, 2012, President Thein Sein asked all Rohingya to be placed in UNHCR refugee camps or to be sent abroad. This was enthusiastically endorsed by Rakhine groups. The All Rakhine Refugee Committee declared that it would refuse any UN or NGO aid. By September 2012, 65,000-70,000 Rohingya were staying in makeshift relief camps after fleeing their homes as a result of the violence. ${ }^{31}$

In late February 2014, the Myanmar government forced Medecins Sans Frontieres (MSF), or Doctors Without Borders, to cease all operations in Rakhine State after the organization spoke publicly about treating Rohingya survivors of a violent attack in Maungdaw Township in January 2014. Under international pressure, the Myanmar government was forced to allow MSF to resume limited operations in January 2015 (see Lowenstein (2015)). According to Amnesty International, more than 750,000 Rohingya refugees, mostly women and children, fled Myanmar and crossed into Bangladesh after Myanmar's state forces launched a crackdown on them in August 2017. Since August 25, 2017, nearly 24,000 Rohingya Muslims were killed by them, according to a report by the Ontario International Development Agency (OIDA).

An international collaborative research effort led to a study interviewing 3,300 Rohingya households living in the makeshift camp in Cox's Bazar, Bangladesh. Using statistical extrapolations based on the survey conducted, the findings of the report present a grim picture of the horrific atrocities perpetrated: they estimated in January 2018 that military and local Rakhine population killed at least 25,000 Rohingya people and carried out gang rapes and other forms of sexual violence against 18,000 Rohingya women and girls. They estimated that 116,000 Rohingya were beaten, and 36,000 were thrown into fires. ${ }^{32}$

\footnotetext{
${ }^{31}$ See Lowenstein $(2015)$ among others.

${ }^{32}$ This is not the only examination of this issue. In October 2018, the Head of a Human Rights Fact-Finding Mission on Myanmar, established in 2017 by the UN Human Rights Council in Geneva, reported examples of atrocities committed against Rohingya Muslims by Myanmar security forces, known as the Tatmadaw, in six villages, which experienced massacres and other killings, including of women, children and the elderly, mass gang rape, burning and looting. The Mission verified similar operations in 54 separate locations across northern Rakhine. At least 392 villages were partially or wholly destroyed and over 725,000 Rohingya fled. The Head labelled the estimates of 10,000 Rohingya deaths as conservative.
} 
The mass exodus of the Rohingya population from Myanmar in 2017 was recognised as the fastest growing refugee influx in the world since the Vietnam war. The longstanding, recurring crackdowns have left an estimated population of only 200,000 in Myanmar of an estimated 2.4 million Rohingya across the world. This mass exodus was described by United Nations officials as ethnic cleansing (Washington Post, October 12, 2017) and genocide (CNN, March 13, 2018). Yet, the Burmese government dismissed these as exaggerated claims, and mentioned instead that "There is no possibility of crimes against humanity, no evidence of ethnic cleansing, as per U.N. accusations". In December 2019, Aung San Suu Kyi stoutly refuted allegations of genocide against the Rohingya at the International Court of Justice in The Hague, stating that such allegations were "incomplete and misleading". ${ }^{33}$ However, Burmese human rights campaigner Maung Zarni believes that Suu Kyi was "defending the indefensible", and her stand drew widespread criticism and condemnation from international organisations and the world community. ${ }^{34}$

Given that the Bamar ethnic group constitutes about $68 \%$ of the Burmese population (while the rest is composed of several small ethnicities), Myanmar fits the description of having high ethnic dominance in terms of our model. By Propositions 1 and 2, such a society would demonstrate neglect of minorities under democracy and (relatively) equal treatment under dictatorship. To be sure, the Rohingya community has been suffering under the military government too, but as noted above, there has been a significant uptick in the violence against them in the recent "democracy" years. This could not have been possible without the (tacit) support of the elected government. This pattern is fairly consistent with the predictions of our theory.

\subsection{India}

One may even apply the core logic of our theory to the Indian context, although transition from democracy to dictatorship (or vice versa) has not occurred there. There have, however, of late been growing concerns about the health of democratic institutions in India. An article in The Economist dated November 28, 2020 highlights the drift towards authoritarianism and institutional decay in India as voiced by Tarunabh Khaitan in "Killing a Constitution with a Thousand Cuts". ${ }^{55}$ While such observations

\footnotetext{
${ }^{33}$ Aung San Suu Kyi Defends Myanmar Against Rohingya Genocide Accusations - The New York Times (nytimes.com).

${ }^{34}$ https://www.aljazeera.com/programmes/upfront/2019/12/myanmar-aung-san-suu-kyidefending-indefensible-191213090832880.html.

${ }^{35}$ The article is also published in Law and Ethics of Human Rights (2020). Khaitan states the following: "What we have now is a wolf in sheep's clothing. There is no full-frontal big-ticket attack on democracy, but there are multiple, simultaneous attacks on all fronts. ...We are sleepwalking into
} 
cast aspersions on India's stature as a liberal democracy, India continues to be an electoral democracy where there has been no suspension of either national or sub-national level elections or decline in voter turnout on the whole over the last decade. However, one may plausibly argue that the notion of a dominant ethnic group ${ }^{36}$ - defined along religious lines - has really crystallised under the recent regime of the current ruling party, the Bharatiya Janata Party (BJP). The rallying cry of 'Hindutva' (ideology focussed on the Hindu religion) has undoubtedly provided a sense of identity for large sections of Hindus throughout the country. The electoral success of the BJP in the last two national elections - in 2014 and 2019 - bear testimony to the efficacy of this pan-India 'Hindutva' platform.

In light of the above, one may consider the pre-BJP regimes as a democracy characterised by a diffused dominant ethnic group, which stands in a marked contrast to the current BJP-ruled State where there is a clearly-defined sizeable dominant ethnic group - namely, the Hindus who endorse the idea of 'Hindutva'. In this sense, under democracy, we have witnessed an increase in the size of the dominant ethnic group with the advent of the BJP at the helm. Our model - specifically, Proposition 1 suggests that such a situation would potentially lead to more ethnic spending at the cost of general public good provision. In other words, greater discrimination against minorities becomes more likely under the current political regime.

There is a growing body of evidence which suggests likewise. Following the election of the National Democratic Alliance in 2014, headed by the BJP, violence fomented by a sense of Hindu religious nationalism has been in the news on a daily basis (see Mitra and Ray (2019)). Among the cases that hit the headlines were the lynching of Mohammed Akhlaq, a Muslim man, in Dadri (a place barely $50 \mathrm{~km}$ from the Indian capital) on 28th September, 2015. A panel from the National Commission for Minorities in India investigated this event and concluded that this lynching - over rumours that he kept and consumed beef - was premeditated. In yet another incident on 17th June, 2019, the hapless 24-year-old Tabrez Ansari was beaten for hours on suspicion of bike theft, while being forced to chant 'Jai Shri Ram' and 'Jai Hanuman' (Glory to Lord Ram and Lord Hanuman) until he died at the hands of a Hindu mob in the eastern state of Jharkhand. ${ }^{37}$ The U.S. Commission for International Human Rights has condemned the lynching of Ansari, observing the recognizable pattern of hate crimes against minorities that marks India's dangerous slide into a majoritarianism, calling

authoritarianism."

${ }^{36}$ Hindus constitute over $80 \%$ of the total Indian population, while Muslims - numbering around 200 million - are the largest religious minority.

${ }^{37}$ Lord Ram and his devotee Lord Hanuman being revered characters in the Hindu pantheon are worshipped widely across India. See https://scroll.in/article/928508/from-ayodhya-to-parliament-avery-short-history-of-jai-shri-ram. 
for the Indian government to take action to prevent further violence. ${ }^{38}$ This systematic uptick in mob lynching in the recent years has been documented by several scholars and its link to BJP's governance has been explored (see e.g., Basu (2021)).

In the Indian case, one may plausibly argue that rather than the religious identity of the political leadership (Hindus have always held the most prominent leadership positions in the major national parties, be it the Indian National Congress or the BJP) it is the systematic conflation of the national identity with the religious one (i.e., Hindus are the "real" Indians by default whereas Muslims need to prove their Indianness) in the recent years which has resulted in a change in the conditions of the Muslim citizens. To explore this idea in greater detail, we embark on a quick comparison of the salient features of two Indian states - specifically, Gujarat and West Bengal.

\subsubsection{Ethnic dominance and public spending: A sub-national analysis}

Both Gujarat and West Bengal (henceforth, WB) have always had Hindu chief ministers since independence, although the proportion of Muslims differs considerably between the two (9.67\% of the population in Gujarat compared to $27.01 \%$ in WB in 2011) ${ }^{39}$ It is important to note that the nature of public goods provision varies considerably between the states, presumably on account of differences in the pattern of demand from the people who elected those governments to power.

Gujarat, one of the wealthiest states in the country, contains only 4.7 per cent of the India population but contributes to 7.9 per cent of the total domestic output of all states. WB is one of the most densely populated states, with 7.2 per cent of the country's population, and produces 5.7 per cent of the domestic output. If one looks at the spending figures for the 2015-20 period, it is clear that Gujarat prioritises sectors like energy, urban development, water supply and sanitation, housing, etc., while WB does the same for rural development and social security. In fact, the difference is quite stark for social security: WB spends $9.4 \%$ while for Gujarat the figure is $0.8 \%{ }^{40}$

The mortality and malnourishment figures reveal this asymmetry even more clearly: the National Family and Health Survey (NFHS) data show that the under-five mortality rate in Gujarat is 37.6 per 1000 births, while that of WB is 25.4. Also, the gap between the proportion of children who are stunted (height-for-age) or underweight (weight-for-

\footnotetext{
${ }^{38}$ See https://thewire.in/communalism/tabrez-ansari-jharkhand-lynching-repox and https://www.business-standard.com/article/pti-stories/us-body-on-religious-freedom-condemnslynching-of-muslim-man-in-jharkhand-119062700098_1.html.

${ }^{39}$ Muslim Religion Census 2011. Link: https://www.census2011.co.in/data/religion/2muslims.html.

${ }^{40}$ Tale of two states: How West Bengal and Gujarat perform at various development indicators DIU News (indiatoday.in)
} 
age) in Gujarat and WB is around 7\%, and this gap has widened over two decades. ${ }^{41}$ These trends can be attributed to the Public Distribution System, which has made significant inroads into the rural areas in WB, as well as a robust local government in the form of the panchayat system, together with primary and high school education for women.

There is also a stark contrast between the two states in terms of documented HinduMuslim violence. Over the 15-year period from 1984 to 1998, the number of people reported to be killed or injured in Hindu-Muslim riots in West Bengal was 219. The corresponding figure for Gujarat is 4499 which is over 20 times the figure for WB (see Mitra and Ray (2014). As Mitra and Ray (2014, 2019) and others argue, the brunt of such violence is borne disproportionately by the minorities, i.e., the Muslims in this context. Hence, the prevalence of religious violence seems to disfavour Muslims more strongly in Gujarat than in West Bengal. The pattern of public spending in Gujarat and WB suggests less general redistribution in the former in relation to the latter, and this is all the more salient given that Muslims are poorer on average in both states. These patterns taken together strongly suggests that the size of the dominant ethnic group (large in Gujarat and relatively small in WB) has a key role in explaining spending patterns and discrimination in a democratic setup. It must be noted that Gujarat has been governed by the BJP over the last few decades while WB has always been headed by a non-BJP government. Our claim is that the asymmetry in the treatment of Muslims in the two states is not merely a reflection of two different political ideologies but also driven by the ethnic demography - specifically, the presence (or not) of a dominant ethnic group - therein. This within-country comparison of the performances and priorities of the two states reveals much that a country-level analysis fails to uncover.

\section{Conclusion}

The issue of discrimination against minorities is of significant interest to scholars from various disciplines and policy-makers. Given the recent interest in the role of institutions on the workings on the economy, it is natural to ask if "superior" institutions like democracy can automatically alleviate such discrimination. Here we have attempted to take on this question with the help of a simple model, whose analysis yields relevant insights. Without doubt, discrimination takes many hues within any ethnically heterogeneous society - our analysis cannot possibly encompass all forms of discrimination. To be specific, we have tried to capture discrimination in public policy in a stylised

\footnotetext{
${ }^{41}$ Why does poor West Bengal have healthier children than rich Gujarat? (scroll.in).
} 
way. In our model, the government (popularly elected or otherwise) is allowed to either engage in public spending on genuinely public goods or on providing what only members of the dominant ethnic group benefit from. In our setup, the existence and exercise of the latter option signifies discrimination. In a sense, our model is essentially geared towards analysing explicit or covert forms of discrimination where the state is an active agent.

We analyse this model under two starkly different political regimes - namely, democracy and dictatorship. Our model brings out the contrast in public spending patterns - specifically, discriminatory spending — by highlighting the tensions that drive behaviour under democracy and dictatorships. A society with a relatively small dominant community (and hence largely diverse) is likely to see a more homogeneous pattern of public spending under democracy as compared to one where the dominant community is a sizeable super-majority. In the latter case, targeting the dominant community, at the expense of the minorities, is enough to guarantee electoral success.

The considerations are altogether different under a dictatorship where the dictator has to think of pre-empting any revolution which is undertaken in the hope of moving to democracy. Here different ethnic groups would have different motives based on what they expect under democracy. This is considerably complicated by the fact that within each ethnic group there is a divergence of interests - based on their economic standing - and this interacts with their ethnic identity to determine which combination of tax rates and public good(s) is most appealing to them.

Our theory is capable of interpreting certain historical events involving regime changes. Our model predicts that such a change would either favour or dis-favour minorities depending upon the size of the dominant ethnic group. We discuss a few instances namely, Rwanda, Indonesia, Myanmar and India - in the framework of our model and observe that our predictions are consistent with these cases.

Coming back to the question regarding democracy mitigating concerns regarding discrimination, our position is not without sufficient scepticism. As our analysis demonstrates, minorities may well face less discrimination under dictatorships. Undoubtedly, we are not claiming that democracy necessarily imposes the "tyranny of the masses". What is quite critical is the size of the dominant ethnic group; and this is a factor which usually changes slowly over time. In conclusion, our findings suggest that extra safeguards (reservation of posts, quotas, etc.) need to be in place so as to rescue minorities from unfair treatment in electoral as opposed to liberal democracies. 


\section{Appendix}

Proof. [Observation 1.] Take any $\lambda \in\left(0,1-\frac{1}{2 \pi}\right.$ ]. This implies that the mass of the $(p, 1-\lambda) \geq 1 / 2$. Start with $\left(t_{A}=t_{B}=1, e_{A}=e_{B}=0, g_{A}=g_{B}=\bar{y}\right)$. Here, each party gets an expected payoff of $1 / 2$. Suppose party $A$ deviates to $\tilde{e}_{A}>0$. This implies that $A$ will definitely lose all the votes from the $(p, 1-\lambda)$-group, since they get a payoff of $\bar{y}$ from party $B$ and $A$ cannot guarantee them that (or anything greater) if $\tilde{e}_{A}>0$. Given that $\pi(1-\lambda) \geq 1 / 2$, this deviation for $A$ is not optimal.

Note, that by setting $\tilde{e}_{A}=t_{A} \bar{y} / \lambda$ for any $t_{A} \in(0,1]$, party $A$ may deliver a payoff greater than $\bar{y}$ to a majority, but never all, of the $\lambda$ group since $f>0$ on the entire real line. This implies, by the continuity of the payoffs in $\lambda$, that such a deviation is not profitable against party $B$ 's policy of $\left(t_{B}=1, e_{B}=0, g_{B}=\bar{y}\right)$ for some interval $\left[1-\frac{1}{2 \pi}, \hat{\lambda}\right]$, where $\hat{\lambda}<1$.

For uniqueness, note the following. In any equilibrium, each party must have an expected payoff of $1 / 2$ since 'mimicry' is always an option for each party. Any equilibrium apart from $\left(t_{A}=t_{B}=1, e_{A}=e_{B}=0, g_{A}=g_{B}=\bar{y}\right)$ necessarily involves at least one party offering a positive amount of $E$. The arguments above establish that any such platform must necessarily yield a payoff lower than $1 / 2$ in the interval $(0, \hat{\lambda}]$ when the other party proposes to spend the entire budget on $G$. Thus, $\left(t_{A}=t_{B}=1, e_{A}=e_{B}=0, g_{A}=g_{B}=\bar{y}\right)$ is the only equilibrium in that $\lambda$-interval.

Proof. [Observation 2.] Start with $\left(t_{A}=t_{B}=1, e_{A}=e_{B}=\frac{\bar{y}}{\lambda}, g_{A}=g_{B}=0\right)$. Here, each party gets an expected payoff of $1 / 2$. Now we consider all possible deviations by A.

Case (i): $A$ chooses $t_{A}=t \in(0,1)$ and $e_{A}=\frac{t \bar{y}}{\lambda}$.

$B$ 's platform yields $\frac{\bar{y}}{\lambda}\left(1+\epsilon_{i}\right)$ to each member of the $\lambda$ group.

Take the $(p, \lambda)$ group. A voter from this group will choose $A$ over $B$ only if

$$
(1-t) y^{p}+\frac{t \bar{y}}{\lambda}\left(1+\epsilon_{i}\right) \geq \frac{\bar{y}}{\lambda}\left(1+\epsilon_{i}\right),
$$

which on re-arranging yields

$$
\epsilon_{i} \leq \frac{\lambda y^{p}}{\bar{y}}-1 .
$$

Now analysing the $(r, \lambda)$ group yields the corresponding condition

$$
\epsilon_{i} \leq \frac{\lambda y^{r}}{\bar{y}}-1 .
$$


Clearly, all of the $1-\lambda$ citizens support $A$ 's platform over $B$ 's. This implies that the payoff to $A$ from this deviation is

$$
1-\lambda+\lambda\left[\pi F\left(\frac{\lambda y^{p}}{\bar{y}}-1\right)+(1-\pi) F\left(\frac{\lambda y^{r}}{\bar{y}}-1\right)\right] .
$$

Note, $F\left(\frac{\lambda y^{p}}{\bar{y}}-1\right)<\frac{1}{2}$ as $\frac{\lambda y^{p}}{\bar{y}}<1$ and $F(0)<\frac{1}{2}$. Hence,

$$
\pi F\left(\frac{\lambda y^{p}}{\bar{y}}-1\right)+(1-\pi) F\left(\frac{\lambda y^{r}}{\bar{y}}-1\right)<\frac{1}{2}
$$

for $\pi$ close to 1 . Let $\pi_{1}$ solve

$$
\pi F\left(\frac{\lambda y^{p}}{\bar{y}}-1\right)+(1-\pi) F\left(\frac{\lambda y^{r}}{\bar{y}}-1\right)=\frac{1}{2} .
$$

Thus, for any $\pi>\pi_{1}$ the payoff from deviating is lower than $1-\lambda / 2$. This, in turn, implies that the payoff to $A$ from the deviation will be lower than $1 / 2$ as long as $\lambda$ is above a threshold. Call this threshold $\lambda_{1}$.

Case (ii): $A$ chooses $t_{A}=1$ and $e_{A} \geq 0$ and $g_{A}>0$.

Let the relative spending on $E$ be captured by the parameter $\omega \in[0,1]$. Take the $\lambda$ group. A voter from this group will choose $A$ over $B$ only if

$$
\frac{\omega \bar{y}}{\lambda}\left(1+\epsilon_{i}\right)+(1-\omega) \bar{y} \geq \frac{\bar{y}}{\lambda}\left(1+\epsilon_{i}\right)
$$

which on re-arranging yields

$$
\epsilon_{i} \leq \lambda-1
$$

Clearly, all of the $1-\lambda$ citizens support $A$ 's platform over $B$ 's. This implies that the payoff to $A$ from this deviation is

$$
1-\lambda+\lambda F(\lambda-1)
$$

As $\lambda<1$ and $F(0)<\frac{1}{2}$, the above payoff is smaller than $1 / 2$ as long as $\lambda$ is above a threshold. Call this threshold $\lambda_{2}$.

Case (iii): $A$ chooses $t_{A}=t \in(0,1)$ and $e_{A} \geq 0$ and $g_{A}>0$.

Let the relative spending on $E$ be captured by the parameter $\omega \in[0,1]$. Take the $(p, \lambda)$ group. A voter from this group will choose $A$ over $B$ only if

$$
(1-t) y^{p}+\frac{t \omega \bar{y}}{\lambda}\left(1+\epsilon_{i}\right)+(1-\omega) t \bar{y} \geq \frac{\bar{y}}{\lambda}\left(1+\epsilon_{i}\right)
$$


which on re-arranging yields

$$
\epsilon_{i} \leq \frac{\lambda\left[(1-t) y^{p}+(1-\omega) t \bar{y}\right]}{\bar{y}(1-t \omega)}-1
$$

Analysing the $(r, \lambda)$ group yields the corresponding condition

$$
\epsilon_{i} \leq \frac{\lambda\left[(1-t) y^{r}+(1-\omega) t \bar{y}\right]}{\bar{y}(1-t \omega)}-1
$$

The above implies that the payoff to $A$ from this deviation is

$$
1-\lambda+\lambda\left[\pi F\left(\frac{\lambda\left[(1-t) y^{p}+(1-\omega) t \bar{y}\right]}{\bar{y}(1-t \omega)}-1\right)+(1-\pi) F\left(\frac{\lambda\left[(1-t) y^{r}+(1-\omega) t \bar{y}\right]}{\bar{y}(1-t \omega)}-1\right)\right] .
$$

Observe that

$$
(1-t) y^{p}+(1-\omega) t \bar{y}=(1-t)\left[y^{p}-\bar{y}\right]+(1-\omega t) \bar{y}<(1-\omega t) \bar{y} .
$$

Hence, the relevant threshold for the $(p, \lambda)$ group involves $\epsilon_{i}<0$. Similarly,

$$
(1-t) y^{r}+(1-\omega) t \bar{y}=(1-t)\left[y^{r}-\bar{y}\right]+(1-\omega t) \bar{y}>(1-\omega t) \bar{y}
$$

Hence, for $\lambda \rightarrow 1$ the relevant threshold for the $(p, \lambda)$ group involves $\epsilon_{i}>0$.

In light of the above,

$$
\pi F\left(\frac{\lambda\left[(1-t) y^{p}+(1-\omega) t \bar{y}\right]}{\bar{y}(1-t \omega)}-1\right)+(1-\pi) F\left(\frac{\lambda\left[(1-t) y^{r}+(1-\omega) t \bar{y}\right]}{\bar{y}(1-t \omega)}-1\right)<\frac{1}{2}
$$

for $\pi$ close to 1 . Let $\pi_{2}$ solve

$$
\pi F\left(\frac{\lambda\left[(1-t) y^{p}+(1-\omega) t \bar{y}\right]}{\bar{y}(1-t \omega)}-1\right)+(1-\pi) F\left(\frac{\lambda\left[(1-t) y^{r}+(1-\omega) t \bar{y}\right]}{\bar{y}(1-t \omega)}-1\right)=\frac{1}{2} .
$$

Thus, for any $\pi>\pi_{2}$ the payoff from deviating is lower than $1-\lambda / 2$. This, in turn, implies that the payoff to $A$ from the deviation will be lower than $1 / 2$ as long as $\lambda$ is above a threshold. Call this threshold $\lambda_{3}$.

Setting $\bar{\pi} \equiv \max \left\{\pi_{1}, \pi_{2}\right\}$ and $\bar{\lambda} \equiv \max \left\{\lambda_{1}, \lambda_{2}, \lambda_{3}\right\}$ yields the required thresholds for $\pi$ and $\lambda$, respectively, and completes the proof.

Proof. [Lemma 1.] Take any $\lambda \in(0,1)$. It must be that $t^{\lambda} \in(0,1]$. Observe, $t^{\lambda} \neq 0$ 
as such a platform against $s_{G}$ gets the support of only $1-\pi$ rich citizens and hence loses. Note, the upper bound on $t$ for the $(r, 1-\lambda)$ group, i.e., $\frac{y^{r}-\bar{y}}{y^{r}+\frac{\psi}{\lambda} \bar{y}}$ is decreasing in $\psi$. Recall,

$$
V \equiv(1-\pi)\left[1-F\left(\frac{\lambda\left[\bar{y}-(1-t) y^{r}\right]}{t \bar{y}}-1\right)\right]+\pi\left[1-F\left(\frac{\lambda\left[\bar{y}-(1-t) y^{p}\right]}{t \bar{y}}-1\right)\right] .
$$

Define $z_{i}(t) \equiv \frac{\bar{y}-(1-t) y^{i}}{t}$ for $i \in\{p, r\}$. Hence, one can rewrite $V$ as

$$
(1-\pi)\left[1-F\left(\frac{\lambda z_{r}(t)}{\bar{y}}-1\right)\right]+\pi\left[1-F\left(\frac{\lambda z_{p}(t)}{\bar{y}}-1\right)\right]
$$

Differentiating the above expression w.r.t. $t$ yields the derivative $V^{\prime}$ which is

$$
\frac{\pi(1-\pi) \lambda\left(y^{r}-y^{p}\right)}{t^{2} \bar{y}}\left[f\left(\frac{\lambda z_{p}(t)}{\bar{y}}-1\right)-f\left(\frac{\lambda z_{r}(t)}{\bar{y}}-1\right)\right] .
$$

As $V$ is a continuous function of $t$ defined over the compact unit interval, we look for the maxima (interior and boundary). We first explore the interior solution. Hence, we look for $t$ such that $V^{\prime}=0$.

$$
V^{\prime}=0 \Rightarrow f\left(\frac{\lambda z_{p}(t)}{\bar{y}}-1\right)=f\left(\frac{\lambda z_{r}(t)}{\bar{y}}-1\right) .
$$

Given the unimodality and symmetry of $F$ around $\bar{\epsilon}$, this implies at the interior optima

$$
\frac{\lambda z_{p}(t)}{\bar{y}}-\bar{\epsilon}=\bar{\epsilon}-\frac{\lambda z_{r}(t)}{\bar{y}} \Rightarrow z_{p}(t)+z_{r}(t)=\frac{2 \bar{\epsilon} \bar{y}}{\lambda} .
$$

Note, $z_{i}^{\prime}(t)=\frac{y^{i}-\bar{y}}{t^{2}}$. So, $z_{p}^{\prime}(t)<0$ and $z_{r}^{\prime}(t)>0$ and $z_{p}^{\prime}(t)+z_{r}^{\prime}(t)>0$. Hence, the solution to $V^{\prime}$ is unique. Differentiating $V^{\prime}$ w.r.t. $t$ for the SOC evaluated at the optima yields $V^{\prime \prime}$ which is:

$$
V^{\prime \prime}=\frac{\pi(1-\pi) \lambda\left(y^{r}-y^{p}\right)}{t^{2} \bar{y}}\left[f^{\prime}\left(\frac{\lambda z_{p}(t)}{\bar{y}}-1\right)\left[\frac{\lambda z_{p}^{\prime}(t)}{\bar{y}}\right]-f^{\prime}\left(\frac{\lambda z_{r}(t)}{\bar{y}}-1\right)\left[\frac{\lambda z_{r}^{\prime}(t)}{\bar{y}}\right]\right] .
$$

Using the unimodality and symmetry of $F$ around $\bar{\epsilon}$, we have at the interior optima

$$
f^{\prime}\left(\frac{\lambda z_{r}(t)}{\bar{y}}-1\right)=-f^{\prime}\left(\frac{\lambda z_{p}(t)}{\bar{y}}-1\right) \text {. }
$$

This implies

$$
V^{\prime \prime}<0 \Longleftrightarrow z_{p}^{\prime}(t)+z_{r}^{\prime}(t)>0 .
$$


Hence, the unique interior solution, if it exists, yields a maximum.

Suppose there is no $t$ such that $V^{\prime}=0$. By the continuity of $V$ in $t$, it must be that either $V^{\prime}<0$ or $V^{\prime}>0$ for every $t$ in $[0,1]$. Observe that as $t \rightarrow 0, z_{p}(t) \rightarrow \infty$. Combining this with $z_{p}^{\prime}(t)<0$, we have that for some $t \in(0,1)-$ call it $t_{z}$ - it is the case that $\frac{\lambda z_{p}(t)}{\bar{y}}=1$. To be precise, $t_{z}$ satisfies the following relation:

$$
\frac{\lambda\left[\bar{y}-\left(1-t_{z}\right) y^{p}\right]}{\bar{y}}=t_{z} .
$$

Moreover, for $t=t_{z}, \frac{\lambda z_{r}(t)}{\bar{y}}<1$.

As $\bar{\epsilon}>0$, it follows that $f(0)>f(x)$ for every $x<0$. Hence, $V^{\prime}>0$ for $t=t_{z}$. This establishes that either there is a unique interior solution or $V^{\prime}>0$ for every $t$ in $[0,1]$. In the latter case, $t^{\lambda}=1$ and hence $t_{0}=\frac{y^{r}-\bar{y}}{y^{r}+\frac{y}{\lambda} \bar{y}}$. In the former case, setting $\psi$ high enough so that $\frac{y^{r}-\bar{y}}{y^{r}+\frac{y}{x} \bar{y}}$ is lower than the unique interior optimum guarantees that $t_{0}=\frac{y^{r}-\bar{y}}{y^{r}+\frac{\psi}{\lambda} \bar{y}}$. This ensures that $V^{\prime}>0$ for every $t \leq t_{0}$. Therefore, any increase in $\psi$ lowers $t_{0}$ and hence $V$. This implies that a higher $\lambda$ is needed for equation (1) to balance. This completes the proof.

Proof. [Lemma 2.] Recall that $t_{0} \equiv \min \left\{t^{\lambda}, \frac{y^{r}-\bar{y}}{y^{r}+\frac{y}{\lambda}}\right\}$. Hence, as $\psi \rightarrow \infty, t_{0}=$ $\frac{y^{r}-\bar{y}}{y^{r}+\frac{y}{\lambda} \bar{y}} \rightarrow 0$ and therefore $V$ approaches $(1-\pi)$. The last implication follows from $\lim _{x \rightarrow \infty} F(x)=1$ and $\lim _{x \rightarrow \infty} F(-x)=0$. Thus, the RHS of equation (1) approaches

$$
(1-\pi)(1-\lambda)+\lambda(1-\pi)=1-\pi<\frac{1}{2} .
$$

By the continuity of $V$ in $\psi$ in the neighbourhood of $\infty$ (as $t_{0}=\frac{y^{r}-\bar{y}}{y^{r}+\frac{\psi}{\lambda} \bar{y}}$ here), $\exists \bar{\psi}>0$ such that the RHS of equation (1) is below $\frac{1}{2} \forall \psi \geq \bar{\psi}$. Hence, there is no $\lambda_{0} \in(0,1)$ which can be a solution to equation (1) for $\psi \geq \bar{\psi}$, thus establishing the lemma.

Proof. [Observation 3.] When $D$ chooses $t_{D}$ and $\mu$ to provide only $E$, the level of $E$ provided is $\frac{t_{D}(1-\mu) \bar{y}}{\lambda}$. Clearly, all poor members of the $(1-\lambda)$ group will revolt as their payoff from this is strictly lower than $\bar{y}$ which is that they obtain under democracy. The rich members of the $(1-\lambda)$ group may or may not revolt depending upon $t_{D}$ and $\mu$.

Consider the different members of the dominant ethnic group. A $(r, \lambda)$ individual will choose $N R$ iff

$$
\left(1-t_{D}\right) y^{r}+\frac{t_{D}(1-\mu) \bar{y}}{\lambda}\left(1+\epsilon_{i}\right) \geq \bar{y} .
$$


Similarly, a $(p, \lambda)$ individual will choose $N R$ iff

$$
\left(1-t_{D}\right) y^{p}+\frac{t_{D}(1-\mu) \bar{y}}{\lambda}\left(1+\epsilon_{i}\right) \geq \bar{y}
$$

Hence, for this choice of policy by $D$, the mass of the rebels from the $\lambda$ group is given by

$$
(1-\pi) F\left(\frac{\lambda\left[\bar{y}-\left(1-t_{D}\right) y^{r}\right]}{t_{D}(1-\mu) \bar{y}}-1\right)+\pi F\left(\frac{\lambda\left[\bar{y}-\left(1-t_{D}\right) y^{p}\right]}{t_{D}(1-\mu) \bar{y}}-1\right) .
$$

Depending upon the decision of the $(r, 1-\lambda)$ group, the mass of rebels and hence the probability of the revolt succeeding is given by

$$
\eta \leq \lambda\left[(1-\pi) F\left(\frac{\lambda\left[\bar{y}-\left(1-t_{D}\right) y^{r}\right]}{t_{D}(1-\mu) \bar{y}}-1\right)+\pi F\left(\frac{\lambda\left[\bar{y}-\left(1-t_{D}\right) y^{p}\right]}{t_{D}(1-\mu) \bar{y}}-1\right)\right]+(1-\lambda) .
$$

This, in turn, implies

$$
(1-\eta) \geq \lambda\left[1-(1-\pi) F\left(\frac{\lambda\left[\bar{y}-\left(1-t_{D}\right) y^{r}\right]}{t_{D}(1-\mu) \bar{y}}-1\right)-\pi F\left(\frac{\lambda\left[\bar{y}-\left(1-t_{D}\right) y^{p}\right]}{t_{D}(1-\mu) \bar{y}}-1\right)\right] .
$$

Hence, D's payoff from this policy is at least

$$
\lambda \bar{y} \mu t_{D}\left[1-(1-\pi) F\left(\frac{\lambda\left[\bar{y}-\left(1-t_{D}\right) y^{r}\right]}{t_{D}(1-\mu) \bar{y}}-1\right)-\pi F\left(\frac{\lambda\left[\bar{y}-\left(1-t_{D}\right) y^{p}\right]}{t_{D}(1-\mu) \bar{y}}-1\right)\right] .
$$

Clearly, $D$ will choose $t_{D}$ and $\mu$ strategically to maximise the above expression. This, in turn, implies that $D$ 's payoff is (weakly) greater than which is obtained by setting $t_{D}=1$ and $\mu=1-\lambda$. The latter payoff is given by $\lambda(1-\lambda) \bar{y} / 2$.

Compare this with the one from setting $t_{D}=\frac{y^{r}-\bar{y}}{y^{r}}(<1)$ and $g_{D}=e_{D}=0$, which is given by $(1-\pi) \bar{y}\left(\frac{y^{r}-\bar{y}}{y^{r}}\right)$ which can be re-written as $\pi(1-\pi) \bar{y}\left(\frac{y^{r}-y^{p}}{y^{r}}\right)$. Observe, that for any given $y_{p}$ and $y_{r}$, this payoff is the highest when $\pi=1 / 2$. By definition, $\pi \in(1 / 2,1)$. Hence, $\pi(1-\pi) \bar{y}\left(\frac{y^{r}-y^{p}}{y^{r}}\right)$ is falling in $\pi$. Moreover, for $\pi \rightarrow 1$, this payoff approaches 0 . Hence, there must be a unique threshold level of $\pi$, such that for any $\pi$ at or above this threshold, $D$ chooses to provide $e_{D}>0$ rather than $g_{D}=e_{D}=0$.

Proof. [OBservation 4.] Consider the $\mu$ and $t_{D}$ which represent the arg max of $\mu t_{D} \bar{y}(1-\eta)$ under P.1e. Now suppose $D$ keeps the same $\mu$ and $t_{D}$ and instead of $E$ provides only $G$. Hence, whichever policy induces a lower mass of rebels (a lower $p$ ) will be better for $D$.

First consider the $(p, \lambda)$ group. Compare the threshold person who is indifferent between $D$ 's policy and what democracy offers her, and do this first for P.1e and then for 
P.1g. Then, contrast the $\epsilon$ cutoff point for this citizen from P.1e with the one obtained from P.1g. Hence, we compare $\frac{\lambda\left[\left(1-t_{D}\right) y^{p}+t_{D}(1-\mu) \bar{y}\right]}{\bar{y}}$ with $\frac{\lambda\left(1-t_{D}\right) y^{p}}{\bar{y}\left[1-t_{D}(1-\mu)\right]}$.

If the former is larger (smaller) than the latter, then P.1g commands greater (lower) support among the $(p, \lambda)$ group than P.1e does. Note,

$$
\frac{\left(\frac{\lambda\left[\left(1-t_{D}\right) y^{p}+t_{D}(1-\mu) \bar{y}\right]}{\bar{y}}\right)}{\left(\frac{\lambda\left(1-t_{D}\right) y^{p}}{\bar{y}\left[1-t_{D}(1-\mu)\right]}\right)}=\frac{\left[\left(1-t_{D}\right) y^{p}+t_{D}(1-\mu) \bar{y}\right]\left[1-t_{D}(1-\mu)\right]}{\left(1-t_{D}\right) y^{p}} .
$$

Observe

$$
\frac{\left[\left(1-t_{D}\right) y^{p}+t_{D}(1-\mu) \bar{y}\right]}{\left(1-t_{D}\right) y^{p}}>1>1-t_{D}(1-\mu) .
$$

Clearly,

$$
\frac{\left[\left(1-t_{D}\right) y^{p}+t_{D}(1-\mu) \bar{y}\right]}{\left(1-t_{D}\right) y^{p}}>\frac{\left[\left(1-t_{D}\right) y^{p}+t_{D}(1-\mu) y^{p}\right]}{\left(1-t_{D}\right) y^{p}}=\frac{1-\mu t_{D}}{1-t_{D}}
$$

Also,

$$
\left(\frac{1-\mu t_{D}}{1-t_{D}}\right) \cdot\left[1-t_{D}(1-\mu)\right]=\frac{1-t_{D}+t_{D}^{2} \mu(1-\mu)}{1-t_{D}}>1 .
$$

Hence, P.1g commands greater support among the $(p, \lambda)$ group than P.1e does.

Now consider the $(r, \lambda)$ group. An analogous comparison of the thresholds implies measuring $\frac{\lambda\left[\left(1-t_{D}\right) y^{r}+t_{D}(1-\mu) \bar{y}\right]}{\bar{y}}$ against $\frac{\lambda\left(1-t_{D}\right) y^{r}}{\bar{y}\left[1-t_{D}(1-\mu)\right]}$.

If the former is larger (smaller) than the latter, then P.1g commands greater (lower) support among the $(r, \lambda)$ group than P.1e does. Note,

$$
\frac{\left(\frac{\lambda\left[\left(1-t_{D}\right) y^{r}+t_{D}(1-\mu) \bar{y}\right]}{\bar{y}}\right)}{\left(\frac{\lambda\left(1-t_{D}\right) y^{r}}{\bar{y}\left[1-t_{D}(1-\mu)\right]}\right)}=\frac{\left[\left(1-t_{D}\right) y^{r}+t_{D}(1-\mu) \bar{y}\right]\left[1-t_{D}(1-\mu)\right]}{\left(1-t_{D}\right) y^{r}} .
$$

Observe

$$
\frac{\left[\left(1-t_{D}\right) y^{r}+t_{D}(1-\mu) \bar{y}\right]}{\left(1-t_{D}\right) y^{r}}>1>1-t_{D}(1-\mu) .
$$

Clearly,

$$
\frac{\left[\left(1-t_{D}\right) y^{r}+t_{D}(1-\mu) \bar{y}\right]}{\left(1-t_{D}\right) y^{r}}<\frac{\left[\left(1-t_{D}\right) y^{r}+t_{D}(1-\mu) y^{r}\right]}{\left(1-t_{D}\right) y^{r}}=\frac{1-\mu t_{D}}{1-t_{D}} .
$$


Also,

$$
\left(\frac{1-\mu t_{D}}{1-t_{D}}\right) \cdot\left[1-t_{D}(1-\mu)\right]=\frac{1-t_{D}+t_{D}^{2} \mu(1-\mu)}{1-t_{D}}>1
$$

Hence, $\exists \hat{y}<y^{r}$ such that

$$
\frac{\left[\left(1-t_{D}\right) y^{r}+t_{D}(1-\mu) \hat{y}\right]\left[1-t_{D}(1-\mu)\right]}{\left(1-t_{D}\right) y^{r}}=1
$$

Thus, as long as $\bar{y} \geq \hat{y}$ then

$$
\frac{\left[\left(1-t_{D}\right) y^{r}+t_{D}(1-\mu) \bar{y}\right]\left[1-t_{D}(1-\mu)\right]}{\left(1-t_{D}\right) y^{r}} \geq 1
$$

Let $\theta \equiv y^{r} / y^{p}$. Clearly, $\theta>1$. Therefore, one can write the average income as

$$
\bar{y}=y^{r}\left[\frac{\pi}{\theta}+(1-\pi)\right]
$$

Notice, a reduction in $\theta$, increases $\bar{y}$ relative to $y^{r}$. Hence, for $\theta$ greater than unity but below some threshold, $\bar{y}$ will exceed $\hat{y}$. Thus, for this range of $\theta, \mathrm{P} .1 \mathrm{~g}$ commands greater support among the $(r, \lambda)$ group than P.1e does.

Since the choice of $\mu$ and $t_{D}$ was constrained to the arg max of $\mu y t_{D} \bar{y}(1-\eta)$ under P.1e, $D$ can (weakly) improve upon this by a suitable choice of these variables under P.1g. This completes the proof.

Proof. [Lemma 3.] D's payoff from choosing $\mu \in(0,1)$ and providing only $G$ is

$$
\mu \bar{y}[1-\lambda[1-F(\lambda(1-\mu)-1)]]
$$

Clearly, $D$ may set $\mu=1$ and that coincides with case (a). Hence, we look to check if there is an interior $\mu$ which provides a higher payoff.

Differentiating the above expression and looking for an interior solution yield the following FOC w.r.t. $\mu$ :

$$
1-\lambda[1-F(\lambda(1-\mu)-1)]=\mu \lambda^{2} f(\lambda(1-\mu)-1)
$$

Note, the LHS is strictly decreasing in $\mu$. The RHS is strictly increasing in $\mu$ as long as $f(x) \geq f^{\prime}(x) \forall x<0$. Also, $f(x) \geq f^{\prime}(x) \forall x<0$ guarantees that the SOC is met, implying that the interior solution is indeed a maximum.

For the interior solution, we require the appropriate boundary conditions. The LHS exceeds the RHS for $\mu=0$. We need the RHS to exceed the LHS for $\mu=1$. This 
implies

$$
\lambda^{2} f(-1)>1-\lambda+\lambda F(-1) .
$$

Consider the logistic distribution $F(x)=\frac{\exp \left(\frac{x-\sigma}{\nu}\right)}{1+\exp \left(\frac{x-\sigma}{\nu}\right)}$ with $\nu=1 / 2$ and $\sigma>0$.

As $\lambda \rightarrow 1$, using this logistic functional form would satisfy the above inequality. Hence, it is possible that for $\lambda \in(\bar{\lambda}, 1), D$ will prefer the interior solution over $\mu=1$. 


\section{References}

Acemoglu, D., Naidu, S., Restrepo, P., and Robinson, J.A. (2014). Democracy Does Cause Growth. NBER Working Paper No. 20004.

Acemoglu, D. and Robinson, J.A. (2006). Economic Origins of Dictatorship and Democracy. Cambridge, UK: Cambridge University Press.

Acemoglu, D., Ticchi, D., and Vindigni, A. (2010). A Theory of Military Dictatorships. American Economic Journal: Macroeconomics, 2(1), pp. 1-42.

Alesina, A., and Drazen, A. (1991). Why are stabilizations delayed? American Economic Review, Vol. 81, 1170-1188.

Alesina, A., and La Ferrara, E. (2005). Ethnic Diversity and Economic Performance. Journal of Economic Literature, Vol. 43, 762-800.

Alesina, A., and Rodrik, R. (1994). Distributive Politics and Economic Growth. Quarterly Journal of Economics, Vol. 109, 465-490.

Alesina, A., Baqir, R., and Easterly, W. (1999). Public Goods and Ethnic Divisions. Quarterly Journal of Economics, Vol. 114, 1243-1284.

Al Jazeera - https://www.aljazeera.com/programmes/upfront/2019/12/myanmar-aungsan-suu-kyi-defending-indefensible-191213090832880.html

Baldwin, K., and Huber, J.D. (2010). Economic versus Cultural Differences: Forms of Ethnic Diversity and Public Goods Provision. American Political Science Review, 104(04), 644-662.

Banerjee, A., and Somanathan, R. (2001). Caste, community and collective action: The political economy of public good provision in india. mimeo, MIT.

Bardhan, P., Mitra, S., Mookherjee, D., and Sarkar, A. (2008). Political participation, clientelism and targeting of local government programs: Analysis of survey results from rural West Bengal. Boston: Department of Economics, Boston University.

Barro, R.J. (1990). Government spending in a simple model of endogenous growth, Journal of Political Economy, 98, S103-25.

Basu, D. (2021). Majoritarian Politics and Hate Crimes Against Religious Minorities: Evidence from India, 2009-2018. World Development, Vol. 146, October 2021, 105540.

Bhavnani, R. (2017). Do the Effects of Temporary Ethnic Group Quotas Persist? Evidence from India. American Economic Journal: Applied Economics, Vol. 9(3), 105-123. 
Blouin, A., and Mukand, S. W. (2019). Erasing Ethnicity? Propaganda, Nation Building and Identity in Rwanda. Journal of Political Economy, Vol. 127(3), 1008-1062.

Burgess, R., Jedwab, R., Miguel, E., and Morjaria, A. (2015). The value of democracy: evidence from road building in Kenya. The American Economic Review, 105(6), 18171851.

Chin, A., and Prakash, N. (2011). The redistributive effects of political reservation for minorities: Evidence from India. Journal of Development Economics, 96(2), 265 $27 \%$.

Deacon, R. (2009). Public good provision under dictatorship and democracy. Public Choice, 139: 241-262.

DIU News - Tale of two states: How West Bengal and Gujarat perform at various development indicators (indiatoday.in).

Esteban, J., and D. Ray (2008), "On the Salience of Ethnic Conflict," American Economic Review 98, 2185-2202.

Fernandez, R., and Levy, G. (2008). Diversity and Redistribution. Journal of Public Economics, 92(5-6), 925-943.

Futagami, K., Morita, Y., and Shibata, A. (1993). Dynamic Analysis of an Endogenous Growth Model with Public Capital, Scandinavian Journal of Economics, 95, 607-25.

Gettleman J., Schultz, K. and S. Raj (2020). In India, Coronavirus Fans Religious Hatred, The New York Times, April 12.

Ghosh, S. and Roy, U. (2004). Fiscal policy, long-run growth, and welfare in a stockflow model of public goods, Canadian Journal of Economics, 37, 742-56.

Jensenius, F. R. (2015). Development from Representation? A Study of Quotas for the Scheduled Castes in India. American Economic Journal: Applied Economics, 7(3), 196-220.

Jha, Saumitra (2018). Trading for Peace. Economic Policy. July, 485-526.

Kingsbury, Damien (2003). Autonomy and Disintegration in Indonesia. Routledge.

Lowenstein, Allard K. (2015). Persecution of the Rohingya Muslims: Is Genocide Occurring in Myanmar's Rakhine State? A Legal Analysis. October. International Human Rights Clinic, Yale Law School.

Miguel, E., and Gugerty, M. K. (2005). Ethnic diversity, social sanctions, and public goods in Kenya, Journal of Public Economics 89.11: 2325-2368.

Mitra, A. (2018). Mandated Political Representation and Redistribution. Economica, 
Vol. 85, Issue 338, pp. 266 - 280.

Mitra, A., and Ray, D. (2014). Implications of an Economic Theory of Conflict: HinduMuslim Violence in India. Journal of Political Economy, Vol. 122, No. 4 (August 2014), pp. 719-765.

Mitra, A., and Ray, D. (2019). Hindu-Muslim Violence in India: A Postscript From the 21st Century. J-P Carvalho, S. Iyer and J. Rubin (eds.).Advances in the Economics of Religion. Volume 158, International Economic Association Series, Palgrave Macmillan, pp 229-248.

Mukand, S.W., and Rodrik, D. (2015). The Political Economy of Liberal Democracy. NBER Working Paper No. 21540.

Muslim Religion Census (2011). Link: https://www.census2011.co.in/data/religion/2muslims.html.

Padro-i-Miquel, G. (2007). The Control of Politicians in Divided Societies: The Politics of Fear, Review of Economic Studies 74(4): 1259-1274.

Pande, R. (2003). Can Mandated Political Representation Increase Policy Influence for Dis-advantaged Minorities? Theory and Evidence from India. The American Economic Review, 93(4), 1132-1151.

Panggabean, S.R, and Smith, B. (2011). Explaining Anti-Chinese Riots in Late 20th Century Indonesia. World Development Vol. 39, No. 2, pp. 231-242, 2011.

Persson, T. (2002). Do Political Institutions Shape Economic Policy? Econometrica, 70 (3): $883-905$.

Prunier, G. (1995), "The Rwanda Crisis: History of a Genocide", Columbia University Press.

Purdey, J. (2006). "Anti-Chinese Violence in Indonesia, 1996-1999". Honolulu, H.I.: University of Hawaii Press. ISBN 978-0-8248-305\%-1.

Rwanda: The Preventable Genocide (refworld.org).

Scroll - Why does poor West Bengal have healthier children than rich Gujarat? (scroll.in). Tajfel, H., Billig, M. G., Bundy, R. P., and Flament, C. (1971). Social categorization and intergroup behaviour, European Journal of social Psychology, 1(2), 149-178.

Tan, Mely G. (2005). "Ethnic Chinese in Indonesia". In Ember, Melvin; Ember, Carol R.; Skoggard, Ian. Encyclopedia of Diasporas: Immigrant and Refugee Cultures Around the World. New York, N.Y.: Springer Media. pp. 795 - $80 \%$.

Tavares, J., and Wacziarg, R. (2001). How Democracy Affects Growth. European 
Economic Review, Vol. 45, 1341-1378.

The New York Times - Aung San Suu Kyi Defends Myanmar Against Rohingya Genocide Accusations (nytimes.com).

Turnovsky, S.J. (1997). Fiscal policy in a growing economy with public capital, Macroeconomic Dynamics, 1, 615-39.

Zakaria, F. (2003). The future of freedom: Illiberal democracy at home and abroad. New York: Norton. 